\title{
Rating Migration and Bond Valuation: Towards Ahistorical Rating Migration Matrices and Default Probability Term Structures
}

\author{
Brian Barnard \\ Correspondence: Brian Barnard, Wits Business School, University of the Witwatersrand (WITS), South Africa. \\ Received: January 17, 2017 \\ doi:10.11114/afa.v5i1.2157 \\ Accepted: December 14, 2018 \\ Available online: January 16, 2019 \\ URL: https://doi.org/10.11114/afa.v5i1.2157
}

\begin{abstract}
The study examines rating migration, and default probability term structures obtained from rating migration matrices. It expands on the use of rating migration matrices with reduced form bond valuation models, by formally delineating the probability of default according to the likely rating paths of a bond, as implied by the rating migration matrix. Further, two alternatives are also considered. First, the cost of default is stipulated as the recovery of par according to the exit rating upon default. Also, in addition to stating the value of a bond in terms of expected cash flows, when considering the probability of default, the value of a bond is alternatively stated as the present value of all likely rating paths of the bond, discounted against the market risk-bearing bond forward rates of the different rating categories. The impact of term structure volatility and rating migration uncertainty on bond valuation is also considered.

It is shown that the relationship between rating migration and default probability is complex, and the default probabilities of different rating categories are time-dependent and not isolated from each other. Also, rating migration resembles a delayed default process that influences default probabilities of subsequent intervals. The implications of a rating migration matrix may perhaps only be fully understood through simulation. This form one of the first points by which to evaluate rating migration matrices. The results of the valuation model show that historical rating migration matrices may not be optimal for pricing bonds ahistorically. A principal premise of the study is the dichotomy between historical values and ahistorical estimates, particularly with regards to rating migration. It is argued that historical estimates face two key shortcomings: they must be able to accurately forecast future rating migration and rating category intensities as a result, and they must specify a method to include rating migration uncertainty. An optimization model is delineated to extract ahistorical rating migration matrices from market prices. This too has implications that should be considered. In light of the above, reduced form models may have an advantage over structural models, in their ability to portray a far more sophisticated default process.
\end{abstract}

Keywords: default probability, default risk, credit risk, rating migration, bond valuation

\section{Introduction}

\subsection{The Factors Impacting Bond Valuation}

Huang and Huang (2012) find that, for investment grade bonds (those with a credit rating not lower than Baa) of all maturities, credit risk accounts for only a small fraction - typically around $20 \%$, and, for Baa-rated 10 -year bonds, in the $30 \%$ range - of the observed corporate-Treasury yield spreads, and it accounts for a lower fraction of the observed spreads for bonds of shorter maturities. For junk bonds, however, credit risk accounts for a much larger fraction of the observed corporate-Treasury yield spreads. Geske and Delianedis (2001) conclude that credit risk and credit spreads are not primarily explained by default and recovery risk, but are mainly attributable to taxes, jumps, liquidity, and market risk factors. Also, Elton et al (2001) reach a similar conclusion that credit spreads are not primarily explained by default and recovery risk.

Merton (1974) hypothesizes that the value of corporate debt is determined by the risk free rate, issue traits and default risk. Fama and French (1993) capture two factors specific to bonds. One common risk in bond returns arises from unexpected changes in interest rates - they proxy for the deviation of long-term bond returns from expected returns due to shifts in interest rates, and note that term-structure variables are likely to play a role in bond returns. The other stated factor is default risk. Whilst extensively modelling liquidity risk, Houweling et al (2005) note interest rate risk and credit risk as principal factors. Elton et al (2004) use a homogeneous group of bonds to minimize risk differences. They show that pricing errors within a group vary with bond characteristics. In particular, they consider default risk, liquidity, 
tax liability, recovery rates, and age.

Grandes and Peter (2005) delineate a currency (risk) premium, a default (risk) premium, and a jurisdiction premium. They find that although firm-specific factors are significant in explaining the risk premium investors demand to hold corporate debt, a much more important part of this premium can be attributed to macroeconomic risk factors of the country in which a firm operates. According to them, the corporate default premium is a function of i) sovereign risk, ii) leverage, iii) firm-value volatility, iv) interest rate volatility, v) remaining time to maturity, and vi) liquidity. Contrasted with more specific credit risk, Delianedis and Geske (2003) delineate market risk as including equity risk, currency risk, interest rate risk, commodity price risk, and asset price risk.

Campbell and Taksler (2003) note equity volatility as factor - both idiosyncratic volatility and systematic or market-wide volatility. They conclude that firm specific equity volatility is an important determinant of the corporate bond spread and that the economic effects of volatility are large. They also suggest including a risk premium on systematic credit risk. Elton et al (2001) state default risk, taxes and systemic risk - compensation for the systematic nature of risk in bond returns. Collin-Dufresne et al (2001) point to local supply-demand shocks that are independent of both changes in credit-risk and typical measures of liquidity. In particular, there seems to exist a systematic risk factor in the corporate bond market that is independent of equity markets, swap markets, and the Treasury market and that seems to drive most of the changes in credit spreads.

Athanassakos and Carayannopoulos (2001) see the factors that impact bond value as default risk, tax, specific issue traits, and short-run deviations from equilibrium. In turn, short-run deviations from equilibrium entails liquidity risk, the business and economic environment and conditions, and temporary imbalances of demand and supply between corporate and treasury bonds. The effects of economic conditions and the business cycle on yield spreads are captured with the use of three proxy variables: the annual rate of change in the consumer price index (inflation rate), the quarterly change in the difference between the 20-year and the three-month treasury yields, and the annual rate of change in industrial production index. In addition, whether maturity should be included as a factor is contested.

Elton et al (2001) argue that, if corporate bond returns move systematically with other assets in the market whereas government bonds do not, then corporate bond expected returns would require a risk premium to compensate for the non-diversifiability of corporate bond risk, just like any other asset. The literature of financial economics provides evidence that government bond returns are not sensitive to the influences driving stock returns. There are two reasons why changes in corporate spreads might be systematic. First, if expected default loss were to move with equity prices, so while stock prices rise default risk goes down and as stock prices fall default risk goes up, it would introduce a systematic factor. Second, the compensation for risk required in capital markets changes over time. If changes in the required compensation for risk affects both corporate bond and stock markets, then this would introduce a systematic influence. They believe the second reason to be the dominant influence. The Fama-French (1993) model employs the excess return on the market, the return on a portfolio of small stocks minus the return on a portfolio of large stocks (the SMB factor), and the return on a portfolio of high minus low book-to-market stocks (the HML factor) as its three factors.

Das and Tufano (1995) state investors are exposed to three risks: interest rate risk, changes in credit risk caused by changes in the credit rating of the issuer of the debt, and changes in credit risk caused by changes in spreads on the debt, even when ratings have not changed. Altman (1996) examines the expected spread change and cost implication due to credit rating migration. In the context of portfolios, Fei et al (2012) note that risk models generally predict for each asset in the portfolio, the corresponding probability of default (PD), exposure at default (EAD) and loss given default (LGD). This is also referred to as credit rating migration risk, or simply credit migration risk. Similarly, Kadam and Lenk (2008) note different estimates for risk capital, derived from loss distributions, which they quantify as Value-at-Risk (VAR) and Expected Loss (EL) for the portfolio at hand. Jarrow et al (1997) model the impact in forward rates - and thus bond value - due to credit rating jumps.

Delianedis and Geske (2003) note that default probabilities and changes in expected default frequencies are important to both the structure and pricing of credit derivatives. All corporate issuers have some positive probability of default. This default probability should change continuously with changes in the firm's stock price and thus its leverage. The value of most fixed income securities is typically inversely related to the probability of default. Investors are concerned about changes in the value of their fixed income securities due to changes in the probability of default, even though the actual default seldom occurs. In fact, fixed income investors may be more concerned with changes in the perceived credit quality of their bond holdings than with actual default. Rating migrations, which offer one reflection of changes in perceived quality of bonds, occur much more frequently than defaults.

Foss (1995) specifically differentiates between credit risk and default risk. He notes that the terms default risk and credit risk are often used interchangeably; however, they are not one and the same. Default risk is defined as the risk that the issuer of a fixed-income security will be unable to make timely payments of interest or principal. This risk, diversified over a portfolio of equally rated securities, leads to an expected default loss. Many of the initial studies on risks and 
returns focus on historical default rates and losses. Although these studies provide valuable insight, default rates and default losses, in isolation, are not paramount. Credit risk is defined as the risk that the perceived credit quality of an issuer will change, although default is not necessarily a certain event. Increased credit risk is reflected in a widening of the yield spread. Credit and default risk are correlated because credit deterioration is almost always a precursor to eventual default; even in the most drastic cases, however, until default actually occurs, the potential for recovery or stabilization cannot be totally discounted. In line with this, Manzoni (2004) makes the point that, while several studies model default and bankruptcy events, no empirical work directly models the probability of a bond having its rating revised. He points out the traditional default mode of thinking of most financial institutions, leading to a consensus view of transitions as non-fundamental economic events.

\subsection{Credit Default Swaps}

With regards to the mechanism of credit default swaps (CDS), Blanco et al (2005) note that the buyer of protection makes periodic payments to the protection seller until the occurrence of a credit event or the maturity date of the contract, whichever is first. If a credit event occurs, the buyer is compensated for the loss incurred as a result of the credit event, which is equal to the difference between the par value of the bond or loan and its market value after default. Similarly, Zhu (2006) states that the protection seller is obliged to buy the reference bond at its par value when a credit event (bankruptcy, obligation acceleration, obligation default, failure to pay, repudiation / moratorium, or restructuring) occurs. In return, the protection buyer makes periodic payments to the seller until the maturity date of the CDS contract or when a credit event occurs, whichever comes first. This periodic payment, which is usually expressed as a percentage (in basis points) of its notional value, is called the CDS spread (or the CDS premium).

Norden and Weber (2009) argue that CDS should reflect pure issuer default risk, and no facility or issue specific risk, making these instruments a potentially ideal benchmark for measuring and pricing credit risk. According to Blanco et al (2005), CDSs contain useful information: i) They are an upper bound on the price of credit risk (while credit spreads form a lower bound) and (ii) CDS prices lead in the price discovery process. Benkert (2004) argues that CDS premia represent primarily a price of default risk, and are in this respect similar to bond spreads. Consequently, CDS premia and bond spreads should be driven by the same factors. A number of studies (Benkert, 2004; Ericsson et al, 2009) indeed consider the same factors of bond valuation to explain CDS premiums. Weistroffer et al (2009) mention that rating agencies use information derived from CDS prices to calculate market implied ratings.

Blanco et al (2005) demonstrate the theoretical relationship between CDS and credit spreads: Begin with a loose approximate arbitrage relation. Suppose an investor buys a T-year par bond with yield to maturity of $\mathrm{v}$ issued by the reference entity, and buys credit protection on that entity for T years in the CDS market at a cost of $p_{C D S}$. The investor has eliminated most of the default risk associated with the bond. If $p_{C D S}$ is expressed annually as a percentage of the notional principal, then the investor's net annual return is $\mathrm{y}-p_{C D S}$. By arbitrage, this net return should approximately equal the T-year risk-free rate, denoted by $\mathrm{x}$. If $\mathrm{y}-p_{C D S}$ is less than $\mathrm{x}$, then shorting the risky bond, writing protection in the CDS market, and buying the risk-free instrument would be a profitable arbitrage opportunity. Similarly, if y $p_{C D S}$ exceeds $\mathrm{x}$, buying the risky bond, buying protection, and shorting the risk-free bond would be profitable. This suggests that the price of the CDS, $p_{C D S}$, should equal the credit spread, $\mathrm{y}-\mathrm{x}$.

Weistroffer et al (2009) also consider the vantage point that, in an ideal world, CDS spreads and risk premia in the bond market should show similar behaviour due to the integration of both markets via the possibility of arbitrage. Given risk premia from bond yields, little should be learned from CDS spreads. In practice though, the two indicators reveal significant differences for various reasons. First, bond yields are influenced by many other factors apart from credit risk, notably interest rate risk and liquidity risk, which require distinct assumptions before their implied probabilities of default can be extracted. Likewise, CDS spreads do not easily translate into default probabilities, due to uncertainties concerning recovery values, counterparty risk or the pricing of specific contractual details. Moreover, CDSs allow credit risk to be separated from interest rate risk, thereby excluding one source of uncertainty in the underlying pricing mechanism. Hence, the two instruments provide for two complementary sources of information. They note that a number of studies conclude that on balance CDS spreads display the more favourable characteristics as a market indicator of distress. Based on rigorous empirical analysis, these studies find that CDS spreads tend to lead the signals derived from bond markets. For riskier credit, CDSs seem to be more liquid than their underlying reference entities, as indicated by lower bid-ask spreads in the CDS market. In addition, anecdotal evidence suggests that CDS trading tends to continue during periods of distress, in times when liquidity in bond markets may be severely restricted.

Blanco et al (2005) find the theoretical relation equating CDS prices to credit spreads forms a valid equilibrium relation for most cases considered. The CDS market leads the bond market in determining the price of credit risk. When examining the determinants of changes in the pricing of credit risk in the two markets, they find that macro-variables (interest rates, term structure, equity market returns, and equity market implied volatilities) have a larger immediate impact on credit spreads than on CDS prices. Conversely, firm-specific equity returns and implied volatilities have a 
greater immediate effect on CDS prices than on credit spreads. However, the equilibrium equivalence of CDS prices and credit spreads implies that both are equally sensitive to the mentioned variables in the long run, and they find that this is achieved through the lagged adjustment of the credit spreads to the CDS prices, confirming the price discovery results.

The analysis of Zhu (2006) confirms the theoretical prediction that CDS prices to credit spreads should be on average equal to each other. However, in the short run there are quite significant pricing discrepancies between the two markets. Credit factors are very important in generating the deviation from the equivalence relationship. Rating events, changes in credit conditions and dynamic adjustments of the two spreads explain most of the short-term price discrepancies. The other factors, such as terms of contracts, liquidity and the short-sale restriction, only have a very small impact. The derivatives market leads the cash market in price discovery only occasionally.

Longstaff et al (2005) use a convenience-yield or liquidity process to capture the extra return investors may require, above and beyond compensation for credit risk, from holding corporate rather than riskless securities. The contractual nature of credit-default swaps makes them far less sensitive to liquidity or convenience-yield effects. The convenience-yield or illiquidity process is applicable to the cash flows from corporate bonds, but not to cash flows from credit-default swap contracts. They use the information in credit-default swaps to provide direct evidence about the size of the default and non-default components in corporate spreads. They find evidence that time variation in corporate spreads is related to systematic liquidity shocks, and that the presence of an aggregate liquidity factor in bond markets may explain most of the movements of credit spreads. Also, the default component represents the majority of corporate spreads. Alternatively, market implied risk-neutral estimates of jump risk may be larger than estimates based on historical data. They also find evidence of a significant non-default component in corporate spreads. This result is robust to the choice of the riskless curve.

They find that the non-default component is time varying and mean reverts rapidly. The non-default component of spreads is strongly related to measures of bond-specific illiquidity such as the bid/ask spread and the outstanding principal amount. In addition, changes in the non-default component are related to measures of Treasury richness such as the on-the-run/off-the-run spread as well as to measures of the overall liquidity of fixed income markets such as the flows into money market mutual funds. In contrast, there is only weak support for the hypothesis that the non-default component is due to taxes.

\subsection{Default Probability}

Zhu (2006) states that, in general, measures of credit risk consist of three building blocks: probability of default (PD), loss given default (LGD) and correlation between PD and LGD.

In order to model default risk, Athanassakos and Carayannopoulos (2001), consider three proxy variables: i) credit rating, which captures the effect of both the probability of default and the recovery rate; ii) time to maturity; iii) the existence of a sinking fund. Both of the latter two proxies should be related to the probability of default.

Campbell and Taksler (2003) note that the literature distinguishes between structural and reduced form models. In structural models, a firm is assumed to default when the value of its liabilities exceeds the value of its assets, in which case bondholders assume control of the company in exchange for its residual value. Reduced form models, by contrast, assume exogenous stochastic processes for the default probability and the recovery rate. The added flexibility of the reduced-form approach allows default risk to play a somewhat greater role in the pricing of corporate bonds.

Merton (1974) shows that for a given maturity, the risk of default varies directly with the variance of the returns on the firm value. In this context, the business cycle and economic environment impact both the level of the risk free rate and the variance of returns on the firm value.

Huang and Huang (2012) consider a credit risk model with a counter-cyclical market risk premium to capture the effects of business cycles on credit risk premia. Secondly, they introduce an analytically tractable jump-diffusion structural credit risk model to capture the effects on credit risk premia of certain future states with both high default risks and abnormally high stochastic discount factors. The second mechanism is distinctly different from the first mechanism. In the model with jumps in asset values, the jumps are unpredictable and there is no time variation in market risk premia.

Altman (1989) notes that analysts have concentrated their efforts on measuring the default rate for finite periods of time - for example, one year - and then averaging the annual rates for longer periods. In almost all previous studies, the rate of default has been measured simply as the value of defaulting issues for some specific population of debt compared with the value of bonds outstanding that could have defaulted. Annual default rates are then usually compared with observed promised yield spreads in order to assess the attractiveness of particular bonds or classes of bonds. A corollary approach is to compare default rates with ex post returns to assess whether investors were compensated for the risks they bear. This approach seeks to measure the expected mortality of bonds in a manner similar to that used by actuaries in assessing human mortality. The use of the term mortality refers specifically to a life expectancy or survival rate for various periods of time after issuance. Although it is informative to measure default rates and losses based on the 
average annual rate method, that traditional technique has at least two deficiencies. It fails to consider that there are other ways in which a bond dies, namely redemptions from calls, sinking funds, and maturation. Therefore, it fails to consider the surviving population of bonds; nor does it answer the question of the probability of default for various time periods in the future on the basis of an issue's specific attributes at issuance, summarized into its bond rating. What is the estimated probability of default and loss from default over a specific time horizon of one year, two years, three years, or $\mathrm{N}$ years?

In line with reduced form models, Elton et al (2001) develop marginal default probabilities from a rating transition matrix employing the assumption that the rating transition process is stationary and Markovian. In year one, the marginal probability of default can be determined directly from the transition matrix and default vector, and is, for each rating class, the proportion of defaults in year one. To obtain subsequent year defaults, they first use the transition matrix to calculate the ratings going into a given year for any bond starting with a particular rating in the previous year. The defaults of that year are then the proportion in each rating class multiplied by the probability that a bond in that class defaults by year end. They find that the marginal probability of default increases for the high-rated debt and decreases for the low-rated debt. This occurs because bonds change rating classes over time.

Elton et al (2001) show that a bond rated AAA has zero probability of defaulting one year later. However, given that it has not previously defaulted, the probability of it defaulting 20 years later is 0.206 percent. In the intervening years, some of the bonds originally rated AAA have migrated to lower-rated categories where there is some probability of default. At the other extreme, a bond originally rated CCC has a probability of defaulting equal to 22.052 percent in the next year, but if it survives 19 years the probability of default in the next year is only 2.928 percent. If it survives 19 years, the bond is likely to have a higher rating. Despite this drift, bonds that were rated very highly at time 0 tend to have a higher probability of staying out of default 20 years later than do bonds that initially had a low rating. However, rating migration means this does not hold for all rating classes. For example, after 12 years the conditional probability of default for CCCs is lower than the default probability for Bs. This is because the odds of being upgraded to investment grade conditional on not defaulting is higher for CCC than B. Eventually, bonds that start out as CCC and continue to exist will be rated higher than those that start out as Bs. In short, the small percentage of CCC bonds that continue to exist for many years end up at higher ratings on average than the larger percentage of B bonds that continue to exist for many years.

Grandes and Peter (2005) note that the rating agencies' main justification for the sovereign ceiling rule - namely, that whenever a government defaults, firms in the country will default as well (i.e., transfer risk is 100 percent) - implies that a 1 percent increase in the government spread should be associated with an increase in the firm spread of at least 1 percent. Market participants may judge transfer risk to be less than 100 percent though. The distinguishing feature of industrial countries - and the United States in particular - is that government bonds are risk-free (i.e., sovereign risk is zero). This is in sharp contrast to emerging markets where - almost by definition - government bonds are not risk-free. In an emerging market, the corporate yield spread above an equivalent government bond yield does not reflect corporate default risk, even after controlling for all other factors. It merely reflects corporate default risk in excess of sovereign default risk. Hence, it appears that in emerging economies there is a crucial additional determinant of corporate default risk: the default risk of the government, i.e., sovereign risk.

When a sovereign is in distress or default, economic and business conditions are likely to be hostile for most firms: the economy will likely be contracting, the currency depreciating, taxes increasing, public services deteriorating, inflation escalating, and interest rates soaring, and bank deposits may be frozen. In particular, the banking sector is more likely than any other industry to be directly or indirectly affected by a sovereign in payment problems. The banks' vulnerability is due to their high leverage (compared to other corporates), their volatile valuation of assets and liabilities in a crisis, their dependence on depositor confidence, and their typically large direct exposure to the sovereign. As a result, default risk of any firm is likely to be a positive function of sovereign risk. They model corporate default probability as the probability that the firm defaults given that the sovereign does not default, plus the probability that the firm defaults given that the sovereign has defaulted.

Fei et al (2012) note a credit rating is a financial indicator of an obligor's level of creditworthiness. Given the relationship between credit ratings and default probability or credit quality, Kumar and Haynes (2003) discuss rating methodology and list the key factors considered as: i) business analysis (industry risk; market position; operating efficiency; legal position), ii) financial analysis (accounting quality; earnings protection; adequacy of cash flows; financial flexibility; interest and tax sensitivity), and iii) management evaluation (track record of management; evaluation of capacity to overcome adverse situations; goals, philosophy and strategies). They find that financial parameters reflect, to a significant extent, the subjective and objective factors used by an expert while rating a debt obligation, with hidden relationships between the financial parameters and associated expert rating.

A number of authors examine the timeliness, accuracy and actual information content of credit rating agencies' ratings 
(Hines et al, 1975; Ederington and Goh, 1998; Amato and Furfine, 2004). Amato and Furfine (2004) mention that rating agencies insist that their ratings should be interpreted as ordinal rankings of default risk that are valid at all points in time, rather than absolute measures of default probability that are constant through time. Delianedis and Geske (2003) note that rating agencies regularly measure the historical default frequency of corporate issuers. While these historical default frequencies are interesting, they are not forward-looking. Option models can provide a forward-looking, risk neutral default probability. Chan and Jegadeesh (2004) point to evidence that agency ratings may not be accurate in a timely fashion.

Studies like Wang (2004) attempt to model default ratings, and studies like Hines et al (1975), Kaplan and Urwitz (1979), Belkaoui (1980) and Chan and Jegadeesh (2004) statistically model bond ratings. This may provide alternative default probability estimates, as structural models also do, relative to the credit ratings of credit rating agencies, but must still be translated to default probability term structures, in a similar way credit agencies' ratings are translated.

In general, bond valuation models - whether structural or reduced form - either use these models to extract default probability estimates from market data, or substitute externally sourced default probability estimates into these models, to determine the magnitude of the default risk component (Eom et al, 2004; Elton et al, 2001; Huang and Huang, 2012; Geske and Delianedis, 2001; Collin-Dufresne et al, 2001). Also, a number of studies quantify credit ratings as proxies of credit quality in terms of spread (Foss, 1995; Kaplan and Urwitz, 1979; Cantor et al, 1997; Perraudin and Taylor, 2004; Chan and Jegadeesh, 2004)

\subsection{Default Probability Term Structures}

Elton (1999) argues that realized returns are a very poor measure of expected returns and that information surprises highly influence a number of factors in an asset pricing model. He believes that developing better measures of expected return and alternative ways of testing asset pricing theories that do not require using realized returns have a much higher payoff than any additional development of statistical tests that continue to rely on realized returns as a proxy for expected returns. He argues that either there are information surprises that are so large or that a sequence of these surprises is correlated so that the cumulative effect is so large that they have a significant permanent effect on the realized mean. Furthermore, these surprises can dominate the estimate of mean returns and be sufficiently large that they are still a dominant influence as the observation interval increases. Thus, the difference between expected and realized returns is viewed as a mixture of two distributions, one with standard properties and the other that more closely resembles a jump process.

Duffie and Singleton (1999) state that, because of the possibility of sudden changes in perceptions of credit quality, particularly among low-quality issues such as Brady bonds, one may wish to allow for surprise jumps in default probability.

Nelson and Siegel (1987) state the range of shapes generally associated with interest rate term structures: monotonic, humped, and S shaped. Related to this, Benkert (2004) consider low interest rates with a recessionary state of the economy. Corporate defaults occur more often during economic downturns than during boom phases, and the occurrence of a recession may cause a decline in credit quality that leads to more defaults in the future. According to this line of reasoning, the compensation for default risk would rise. Duffie and Singleton (1999) note strong evidence that hazard rates for default of corporate bonds vary with the business cycle. Equally, recovery data also exhibit a pronounced cyclical component. Das and Tufano (1995) allowed recovery to vary over time so as to induce a non-zero correlation between credit spreads and the riskless term structure. However, for computational tractability they maintained the assumption of independence of the hazard rate (default rate) and risk-free rate.

Huang and Huang (2012) argue that a credit risk premium is required by investors because the uncertainty of default loss should be systematic - bondholders are more likely to suffer default losses in bad states of the economy. Moreover, precisely because of the tendency for default events to cluster in the worst states of the economy, the credit risk premium can be potentially very large. Athanassakos and Carayannopoulos (2001) note that yield spreads are greater during recessions than during recoveries, and also point to the link between the behaviour of yield spreads to the shape of the term structure, as a proxy of the business cycle. They confirm the typical direct relationship between default risk and yield spreads, and show that the impact of the business cycle (macro-economy) on the yield spread of a corporate bond depends on the industry sector to which the issuer of the bond belongs. The inflation rate should be directly related to yield spreads, since during inflationary periods investors may require higher risk premia from their investments in corporate bonds.

Athanassakos and Carayannopoulos (2001) use the change in the shape of the term structure of interest rates represented by the quarterly change in the difference between the 20 -year treasury rates and the three month t-bill rates as a proxy for the business cycle, since much research in the past has linked the shape of the treasury term structure to future variations in the business cycle. A steepening term structure is a typical result of robust economic growth and 
lower short term interest rates and reflects a general belief in a more robust economic future. The opposite is true when the term structure is flattening or turns negatively sloped. Therefore, the particular proxy should be negatively related to yield spreads. Finally, the annual rate of change in the industrial production index should be negatively related to yield spreads since increased economic activity will bolster investors' confidence in the corporate sector, and lead to a reduction in the risk premia demanded for investment in corporate bonds.

Amato and Furfine (2004) argue that financial market participants behave as if risk is countercyclical, e.g. at its highest during economic downturns. Empirical models, too, tend to indicate a rise in risk during recessions. There is a relationship between the correlation of default rates and loss in the event of default and the business cycle. Models that assume independence of default probabilities and loss given default will tend to underestimate the probability of severe losses during economic downturns. They delineate the empirical significance of the procyclicality of credit quality changes by showing that estimated credit losses are much higher in a contraction relative to an expansion.

Delianedis and Geske (2003) note the term structure of default probabilities could be interesting for examining the changing credit structure of either individual firms, industries, or the whole economy. Thus, a term structure of default probabilities could contain information about the business cycle. Typically, the term structure of unconditional default probabilities should be upward sloping because the probability of default over a specific time horizon increases with time. However, the term structure of default probabilities would be inverted when the short term default probability is greater than the forward default probability. This may occur whenever the firm has a high probability of defaulting in the short term, but if it can survive through the next year and payoff its short term obligations, then the firm's default probability might decline. In this situation, the forward default probability would be less than the short term default probability. The short probability relates to the probability of only defaulting on the short term debt, and the forward probability held today relates to the probability of defaulting on the long term debt, conditional on not defaulting on the short term debt.

Longstaff and Schwartz (1995) argue that the corporate yield spread should vary inversely with the benchmark treasury yield, and find evidence to support this. Kim et al (1993) show that default risk is not particularly sensitive to the volatility of interest rates but is sensitive to interest rate expectations. Campbell and Taksler (2003) note idiosyncratic volatility can move very differently from market-wide volatility. Movements in idiosyncratic risk are more persistent than movements in market risk. Lando and Skødeberg (2002) note that it is likely that macroeconomic variables or other indicators of the business cycle influence rating intensities.

Hamilton and Cantor (2004) raise the notion of a credit cycle. This can be studied parallel to business cycles.

A number of studies model default probability term structures as instantaneous stochastic processes (Das and Tufano, 1995; Duffee, 1999; Jarrow et al, 2002) . For example, Duffee (1999) uses the extended Kalman filter to fit yields on bonds issued by individual investment-grade firms to a model of instantaneous default risk. Das and Tufan (1995) and Jarrow et al (1997) model default risk as Markov chains or trees. Jarrow and Turnbull (1995) exogenously specify a stochastic process for the evolution of the default-free term structure and the term structure for risky debt.

Duffee (1999) argues that at each instant there is some probability that a firm defaults on its obligations. Both this probability and the recovery rate in the event of default may vary stochastically through time. The stochastic processes determine the price of credit risk. Although these processes are not formally linked to the firm's asset value, there is presumably some underlying relation. The instantaneous probability that a given firm defaults on its obligated bond payments follows a translated single-factor square-root diffusion process, with a modification that allows the default process to be correlated with the factors driving the default-free term structure. Realistically there are a number of factors other than default risk that drive a wedge between corporate and Treasury bond prices, such as liquidity differences, state taxes, and special repo rates. Here, all of these factors are substituted into a stochastic process called a default risk process. Default risk is negatively correlated with default-free interest rates. In addition, for the typical firm, the instantaneous risk of default has a lower bound that exceeds zero. In other words, even if a firm's financial health dramatically improves, the model implies that yield spreads on the firm's bonds remain positive.

Duffee (1999) first models the price of a risk-free bond as given by the expectation, under the equivalent martingale measure, of the cumulative discount rate between $t$ and $T$. The discount rate follows a stochastic process - the sum of a constant, and two factors that follow independent square-root stochastic processes. He then models the adjusted discount rate for bond issues that can default, relative to risk-free bonds. This setup is designed to capture three important empirical features of corporate bond yield spreads. The most obvious is that the spreads are stochastic, fluctuating with the financial health of the firm. The second feature is that yield spreads for very high-quality firms are positive, even at the short end of the yield curve. This fact suggests that regardless of how healthy a firm may seem, there is some level below which yield spreads cannot fall. The third feature is that yield spreads, especially spreads for lower quality bonds, appear to be systematically related to variations in the default-free term structure. 
Houweling and Vorst (2005) note reduced form models that use time series estimation to model the hazard rate stochastically, typically as a Vasicek or CIR process. Also, other reduced form models use cross-sectional estimation and consider either constant or stochastic hazard rates, where the stochastic process is chosen in such a way that the survival probability curve is known analytically. Houweling and Vorst (2005) follow an intermediate approach by using a deterministic function of time to maturity. This specification facilitates parameter estimation, while still allowing for time-dependency. They model the integrated hazard function as a polynomial function of time to maturity, with three degrees - linear, quadratic and cubic.

Das and Tufano (1995) choose to make recovery rates correlated with the term structure of interest rates. This results in a model wherein credit spreads are correlated with interest rates, as is evidenced in practice. In the Jarrow-Lando-Turnbull model credit spreads change only when credit ratings change, whereas in the debt markets it is found that credit spreads change even when ratings have not changed. Injecting stochastic recovery rates into the model provides this extra feature.

Hamilton and Cantor (2004) point out the strong stochastic processes associated with rating transitions. Altman and Rijken (2004) investigate the through-the-cycle methodology that agencies use. Through the cycle ratings are stable because they are intended to measure the risk of default over long investment horizons, and because they are changed only when agencies are confident that observed changes in a company's risk profile are likely to be permanent. Investors believe that ratings should reflect changes in credit quality, even if they are likely to be reversed within a year. At the same time, investors want to keep their portfolio rebalancing as low as possible and desire some level of rating stability. This leaves two conflicting goals - rating timeliness and rating stability. The objective of agencies is to provide an accurate relative (ordinal) ranking of credit risk at each point in time, without reference to an explicit time horizon. The through-the-cycle rating methodology of agencies is designed to achieve an optimal balance between rating timeliness and rating stability. The methodology has two key aspects: first, a long-term default horizon and, second, a prudent migration policy. These two standpoints are aimed at avoiding excessive rating reversals, while holding the timeliness of agency ratings at an acceptable level. Compared to point-in-time ratings, agency ratings are aimed at ignoring temporary shocks.

In relation to credit rating migration matrices, Altman (1996) assesses the rating change experience of corporate bonds from two different initial states: i) from the time of issuance to up to ten years post-issuance, and ii) from a static-pool of issuers of a given rating, regardless of the bonds' ages, to up to ten years after the pool is formed. In contrasting unexpected and expected rating migration, he notes the standard deviation around the expected value could be calculated.

Frydman and Schuermann (2008) note that, despite overwhelming evidence to the contrary, credit migration matrices, used in many credit risk and pricing applications, are typically assumed to be generated by a simple Markov process. In their paper they propose a parsimonious model that is a mixture of (two) Markov chains. They estimate this model using credit rating histories and show that the mixture model statistically dominates the simple Markov model and that the differences between two models can be economically meaningful. The non-Markov property of their model implies that the future distribution of a firm's ratings depends not only on its current rating but also on its past rating history. They find that two firms with identical current credit ratings can have substantially different transition probability vectors.

Lando and Skødeberg (2002) contrast rating migration matrices captured by means of a discrete-time estimator, and continuous-time estimator. The continuous-time estimator captures the chance of defaulting within a year after successive downgrades, even if it did not happen for one single firm in the sample, whereas the discrete-time method does not. It is shown that rating migration matrices from these different methods differ significantly. They present a rigorous formulation of the notion of rating drift - a type of non-Markovian behavior - in the process of ratings and find strong non-Markov effects for downgrades.

Nickell et al (2000) use Moody's data from 1970 to 1997 to examine the dependence of ratings transition probabilities on industry, country and stage of the business cycle using an ordered probit approach, and they find that the business cycle dimension is the most important in explaining variation of these transition probabilities. They point out that rating transition matrices vary according to the stage of the business cycle, the industry of the obligor and the length of time that has elapsed since the issuance of the bond. Kadam and Lenk (2008) identified strong differences in rating migration behaviour between issuers of different industry sectors and countries.

Bangia et al (2002) argue that credit migration matrices provide the specific linkage between underlying macroeconomic conditions and asset quality. Credit migration matrices characterize the expected changes in credit quality of obligors. Total volatility (risk) is composed of a systematic and an idiosyncratic component. Because ratings are a reflection of a firm's asset quality and distance to default, a reasonable definition of "systematic" is the state of the economy. They find distinct differences between the U.S. expansion and contraction transition matrices. The most striking difference between expansion and contraction matrices are the downgrading and especially the default 
probabilities that increase significantly in contractions. Overall, these results reveal that migration probabilities are more stable in contractions than they are on average, supporting the existence of two distinct economic regimes. The rating universe should develop differently in contraction periods compared to expansion times.

The straightforward application of these matrices however would normally be restricted to situations where the future state of the economy over the transition horizon under consideration is assumed to be known. The state of the economy clearly is one of the major drivers of systematic credit risk, especially as lower credit classes are much more sensitive to macro-economic factors. Consequently it should be integrated into credit risk modeling whenever possible, otherwise the downward potential of high-yield portfolios in contractions might be severely underestimated. Modern credit risk models account for different industries only through different term structures, but not through industry dependent transition matrices.

Fei et al (2012) proposes an approach to estimate credit rating migration risk that controls for the business-cycle evolution during the relevant time horizon in order to ensure adequate capital buffers both in good and bad times. The approach allows the default risk associated with a given credit rating to change as the economy moves through different points in the business cycle. They mention a body of research linking portfolio credit risk with macroeconomic factors showing, for instance, that default risk tends to increase during economic downturns. Their premise is that point-in-time methodologies that account for business cycles should provide more realistic credit risk measures than through-the-cycle models that smooth out transitory fluctuations (perceived as random noise) in economic fundamentals.

The naïve approach to accommodating cyclicality subdivides the historical ratings into those observed in normal, peak and trough regimes according to real GDP growth and deploys a discrete time (cohort) estimator of migration risk separately on each sub-sample. In effect, the naïve estimator implicitly assumes that the current economic conditions prevail throughout the prediction time horizon of interest. They relax this assumption by allowing the economy to evolve randomly between states of the business cycle during the risk horizon, and evaluate a MMC estimator against a naïve counterpart that conditions deterministically on the current economic conditions by assuming that they prevail throughout the prediction time horizon, and against classical through-the-cycle estimators. Such studies consider economic dynamics in credit risk modelling, by assessing the estimators in a strictly forward-looking sense. In contrast, they exploit a real-time leading indicator of business cycles based on a principal components methodology to generate out-of-sample predictions of credit migration risk. Acknowledging the risk that economic conditions randomly evolve over the risk horizon is shown to improve the accuracy of out-of-sample default probability predictions. Ignoring business cycles significantly understates default risk during economic contraction.

Elton et al (2004) consider factors that affect individual issue prices, as part of homogeneous groups of bonds. They then assume that each of the variables considered could effect the level but not the shape of the corporate term structure. For example, it is assumed that the Baa+ and Baa- spot term structure curves are parallel to each other and the Baa spot term structure curve. They note that, to the extent that this simplification of the effect of variables is inappropriate it will bias their results against attributing importance to the influences they examine. Also, there exists significant correlation between homogeneous corporate term structures, in that such term structures generally lay parallel to each other, and perhaps even the market corporate term structure. A number of studies also allude to some correlation between risk-bearing term structures and default probability term structures (Elton et al, 2001; Eom et al, 2004).

\subsection{A Rating Migration Based Valuation Model}

\subsubsection{A Rating Migration Based Reduced Form Model for Zero-Coupon and Coupon Paying Risk-Bearing Bonds}

Equation 1 states the reduced form model of Duffie and Singleton (1999), adapted for coupon paying bonds. Equation 1 has two components, a coupon paying component associated with non-default outcomes, and a recovery component associated with default outcomes.

In the equation, $V$ is the price or value of the risk-bearing bond; $M$ is the number of coupons of the bond, including par; $C_{m}$ is the coupon of the bond on coupon date $m ; R$ is the recovery of par value; $r_{t_{m}}^{r f}$ and $t_{m}$ are the risk-free spot rate and time value, respectively, associated with coupon date $m ; h_{n}$ is the default probability of interval $n$, conditional on no default prior to interval $n ; P_{m}$ is the cumulative non-default probability of interval $m ; J_{m}$ is the number of probability intervals for which the possibility of default is considered up to coupon date $m$; $J_{M}$ is the number of probability intervals considered up to maturity.

For coupon paying bonds, it is convenient to consider $J_{m}$ and $J_{M}$ to be equal to $m$ and $M$. For example, the third coupon may have three probability intervals leading up to it. For zero-coupon bonds, $M$ is equal to 1 , and $J_{M}$ may be greater than $M$, with $J_{m}$ not necessarily corresponding with $m$; a regular coupon interval may still be considered though to ensure a timely and consistent consideration of default. A five-year zero coupon bond will have only one 
coupon, but can have up to ten probability intervals leading up to it, if semi-anual probability intervals are used.

$$
\begin{gathered}
V=\sum_{m=1}^{M}\left(\prod_{n=1}^{J_{m}}\left(1-h_{n}\right) e^{-r_{t_{m}}^{r f} t_{m}} C_{m}\right)+\sum_{j=1}^{J_{M}}\left(\prod_{n=1}^{j-1}\left(1-h_{n}\right) h_{j} e^{-r_{t_{j}}^{r f} t_{j}} R\right) \\
\prod_{n=1}^{j-1}\left(1-h_{n}\right)=1 ; j-1<1 \\
P_{m}=\prod_{n=1}^{J_{m}}\left(1-h_{n}\right) \\
\prod_{m=1}\left(1-h_{n}\right)-\prod_{n=1}^{J_{m}-1}\left(1-h_{n}\right)=\prod_{n=1}^{J_{m}}\left(1-h_{n}\right)\left(1-\left(1-h_{J_{m}}\right)\right)=\prod_{n=1}^{J_{m}-1}\left(1-h_{n}\right) h_{J_{m}} \\
V=\sum_{m=1}^{M} P_{m} e^{-r_{t_{m}}^{r f} t_{m}} C_{m}+\sum_{j=1}^{J_{m}-1} P_{j \mid j-1} e^{-r_{t_{j}}^{r f} t_{j}} R
\end{gathered}
$$

Although not explicitly stated by them, equation 2 delineates the default probability structure implemented by Elton et al (2001). They subsequently substitute this into a reduced form model similar to equation 1 .

cat non-default are all non-default rating categories; $I_{\text {Path }_{m}}$ is the intensity or propensity of path or tree Path $_{m}$ that leads up to interval $m$; similarly, $I_{j}^{\text {Path }}$ is the path intensity or propensity of path $j ; I_{m}^{c a t_{n}}$ is the intensity or propensity of rating category $n$ in interval $m$; Path default is the number of default paths of (up to) interval $m$; $P a t h_{m}^{\text {non-default }}$ is the number of non-default paths of interval $m$; contrary to a default path, a non-default path can not and does not end up in default over its length or run; $P a t h_{m \mid \rightarrow k}^{\text {non-default }}$ is the number of non-default paths that migrate to - end with - category kin interval $m ; P_{b_{(n-1)} m i g \mid n}^{m}$ is the probability of migration from rating $b_{n-1}$ in interval $n-1$ to rating $b_{n}$ in interval $n ; P_{k \rightarrow n}^{m i g \mid m}$ is the probability of migration from category $k$ to category $n$ in interval $m ; P_{k \rightarrow \text { default }}^{\text {mig } \mid m}$ is the probability of category $k$ migrating to default status in interval $m ; h_{n}$ is again the default probability of interval $n$, conditional on no default prior to interval $n$.

$$
\begin{aligned}
& I_{P a t h_{m}}=\prod_{n=1}^{J_{m}} P_{b_{(n-1)}}^{m i g \mid n} \rightarrow b_{n} \\
& I_{m}^{\text {cat }}{ }_{n}=\sum_{k=1}^{\text {cat }} \sum_{j=1}^{\text {non-default Path }}{ }_{\substack{\text { non-default } \\
m-1 \mid \rightarrow k}}^{\text {Path }} P_{k \rightarrow n}^{\text {mig } \mid m}=\sum_{k=1}^{\text {cat }} \sum_{m-1}^{\text {non-default }} I_{k \rightarrow n}^{\text {cat }} P_{k}^{\text {mig } \mid m} \\
& \prod_{n=1}^{m}\left(1-h_{n}\right)=\sum_{n=1}^{\text {Pat } h_{m}^{\text {non-default }}} I_{n}^{\text {Path }}=\sum_{n=1}^{\text {cat }{ }^{\text {nor }} \text { default }} I_{m}^{\text {cat }}{ }^{n} \\
& \prod_{n=1}^{m-1}\left(1-h_{n}\right) h_{m}=\sum_{k=1}^{{ }^{\text {cat }}{ }^{\text {non-default }} \sum_{j=1}^{\text {Path }} \sum_{m-1 \mid \rightarrow k}^{\text {non-default }}} I_{j}^{\text {Path }} P_{k \rightarrow \text { default }}^{\text {mig } \mid m}=\sum_{k=1}^{{ }^{\text {cat }}{ }^{\text {non-default }}} I_{m-1}^{\text {cat }} P_{k \rightarrow \text { default }}^{\text {mig }}
\end{aligned}
$$




$$
h_{n}=1-\left(\prod_{m=1}^{n}\left(1-h_{m}\right) / \prod_{m=1}^{n-1}\left(1-h_{m}\right)\right)=\left(\sum_{k=1}^{\text {cat }} I_{n-1}^{\text {non-default }} P_{k \rightarrow \text { default }}^{\text {cat }}\right) /\left(\prod_{m=1}^{n-1}\left(1-h_{m}\right)\right)
$$

Equation 3 allows the recovery rate to depend on the rating category the bond is in when it defaults. Moving from equation 1.4 to equation 3.1 is further explained by equation set $2 . R_{m}^{n}$ is the recovery of par value of rating category $n$ in interval $\mathrm{m}$.

$$
V=\sum_{m=1}^{M} P_{m} e^{-r_{t_{m}}^{r f} t_{m}} C_{m}+\sum_{j=1}^{J_{M}} \sum_{n=1}^{\text {cat }} I_{j-1}^{\text {non-default }} P_{n \rightarrow \text { default }}^{\text {mig } \mid j} e^{-r_{t_{j}}^{r f} t_{j}} R_{j}^{n}
$$

By using a value loss description, equation 1 is rewritten as the sum of all promised cash flows, discounted at the risk-free rate, minus the present value of value lost due to default. It is expected that equation 4 should yield a similar value than equation 1.

$V_{m}^{r f \mid a}$ is the risk-free based value of a bond with rating category $a$, in interval $m ; F V_{m}^{r f \mid a}$ is the risk-free based future value of a bond of rating category $a$, in interval $m ; \Delta V_{m}^{a} \rightarrow$ default is the change in value due to a bond of rating category $a$ defaulting in interval $m ; r_{n \mid m}^{r f}$ is the risk-free forward rate over the interval demarcated by point in time $n$ and $m ; R_{m}^{n}$ is the recovery of par value of rating category $n$ in interval $m ; I_{m}^{c a t_{n}}$ is the intensity or propensity of rating category $n$ in interval $m ; P_{k \rightarrow \text { default }}^{m i g \mid n}$ is the probability of category $k$ migrating to default status in interval $n ; r_{t_{m}}^{r f}$ and $t_{m}$ are the risk-free spot rate and time value, respectively, associated with coupon date $m$; $P V(x)$ refers to the present value of $x$; cat ${ }^{\text {non-default }}$ are all non-default rating categories; $k_{m}$ is the number of coupons remaining at (after) interval $m$.

$$
\begin{aligned}
& V_{m}^{r f \mid a}=F V_{m}^{r f \mid a}=\sum_{n=k_{m}}^{M} e^{-r_{n \mid m}^{r f} t_{m}^{n}} C_{n} \\
& \Delta V_{m}^{a \rightarrow \text { default }}=I_{m-1}^{\text {cat }_{a}} P_{a \rightarrow \text { default }}^{\text {mig } \mid m}\left(V_{m}^{r f \mid a}-R_{m}^{a}\right) \\
& V=\sum_{m=1}^{M} e^{-r_{t_{m}}^{r f} t_{m}} C_{m}-\sum_{j=1}^{J_{M}}\left(\sum_{n=1}^{{ }^{c a t}{ }^{\text {non-default }} I_{j-1}^{\text {cat }}{ }_{n}} P_{n \rightarrow \text { default }}^{\text {mig } P} P\left(V_{j}^{r f \mid n}-R_{j}^{n}\right)\right) \\
& V=\sum_{m=1}^{M} e^{-r_{t_{m}}^{r f} t_{m}} C_{m} \sum_{j=1}^{J_{M}}\left(\sum_{n=1}^{c a t^{n o n-d e f a u l t}} I_{j-1}^{c a t_{n}} P_{n \rightarrow \text { default }}^{\text {mig } \mid j}\left(e^{-r_{t_{j}}^{r f} t_{j}} R_{j}^{n}-\sum_{n=1}^{\text {cat non-default }} V_{j}^{r f \mid n} e^{-r_{t_{j}}^{r f} t_{j}}\right)\right)
\end{aligned}
$$

1.5.2 Credit Quality Deterioration, Rating Migration, and Valuation According to Rating Migration

In certain markets, like the South African market, credit spreads persist, yet the market has experienced very low default rates. Not all (few) corporate bonds in this market have top credit ratings assigned to them by credit agencies, and credit spreads abound. At the same time, historically very few actual defaults have occurred, such that a rating migration matrix based on historical data would have extremely low probability of migration to default per credit rating category.

In light of credit risk being synonymous with credit quality, equation 5 rather values a bond according to its likely future credit ratings and thus credit quality. Bonds may very well migrate to a lower rating and thus credit quality, and remain there for some time, without defaulting immediately, or defaulting at all - the bond has merely migrated to a higher probability of default, and a rating homogeneous portfolio the bond forms part of, is expected to honour this probability of default estimate.

A rating degradation implies a degradation of credit quality, that implies a loss of resell value and an increased 
probability of default in the future. For a risk-neutral investor to be indifferent to the investment period, future credit quality must be adequately anticipated. Credit quality changes in the form of rating migration may cause an investor to reconsider holding a security, particularly in light of expected future ratings and thus credit quality, if it was not properly included in the valuation beforehand. This implies that the investor is not insensitive - but indeed sensitive - to the investment period.

Thus, a bond may also be valued according to its probable future rating states, which corresponds to the rating migration paths of equation 2. In addition, this should produce a result comparable to a valuation that considers expected cash flows, when considering the risk of default (equation 1,3 and 4). The duration of a bond in a particular rating category is valued against the forward rate of that category for the given duration or interval. The value of a bond is thus seen as the sum of the present value of all possible future rating states, according to all possible rating migration paths (equation 5.2). For this purpose, a rating migration matrix is still used. Practically, the study uses the market risk-bearing term structures to value these future rating states.

As equation 5.4 and 5.5 reflect, the forward rate applicable over a particular rating migration path is seen as an extra weight or attenuation factor, such that that the intensity or propensity of a particular sub-path - and thus path - is simply the probability of the path multiplied by the applicable forward rate.

Much of the terms correspond to that of previous equations. $M$ is the number of coupons of the bond, including par value; $C_{m}$ is the bond coupon corresponding to coupon date $m ; R$ is the recovery of par value; $R_{m}^{n}$ is the recovery of par value of rating category $n$ in interval $m$; cat $t^{\text {non-default }}$ are all non-default rating categories; $P a t h_{m \mid \rightarrow k}^{\text {non-default }}$ is the number of non-default paths that migrate to - end with - category $k$ in interval $m$; Path $h_{m}^{\text {default }}$ is the number of default paths of interval $m$; Path hon-default is the number of non-default paths of interval $m$; $P_{k}^{\text {Path }}$ is the probability of path $n$ over interval $k ; t_{k-1}^{k}$ is the time interval length between interval $k$ and $k-1$; $D F_{m \mid n}^{a}$ is the discount factor of rating category $a$ over the interval demarcated by point in time $m$ and $n$ - this also corresponds with the forward rate of the rating category over the interval; $D F_{k \mid k-1}^{P a t h_{n}}$ is the discount factor of path $n$ over the interval $(k-1, k)$, which equals the forward over the particular interval; $f_{m \mid m-1}^{n}$ is the forward rate of rating category $n$ over the interval $m$ and $m-1 ; f_{k}^{\text {Path } \mid n}$ is the forward rate of path $n$ over interval $k ; I_{\text {Path }_{t}}^{d f}$ and $I_{l}^{d f \mid \text { Path }}$ are the forward rate based path intensity or propensity of path $l ; I_{m}^{d f \mid c a t_{n}}$ is the forward rate based intensity or propensity of rating category $n$ in interval $m ; P_{k \rightarrow n}^{m i g \mid m}$ is the probability of migration from category $k$ to category $n$ in interval $m ; J_{m}$ is the number of probability intervals considered up to coupon date $m$.

$$
\begin{gathered}
D F_{m \mid n}^{a}=D F_{m \mid 0}^{a} / D F_{n \mid 0}^{a}=e^{-r_{m}^{a} t_{m}+r_{n}^{a} t_{n}} \\
V=\sum_{m=1}^{M}\left(\sum_{n=1}^{\text {Path }_{m}^{\text {non-default }}}\left(\prod_{k=1}^{J_{m}} P_{k}^{\text {Path }} \prod_{k=1}^{J_{m}} D F_{k \mid k-1}^{\text {Path }}\right) C_{m}\right) \\
V=\sum_{m=1}^{M}\left(\sum _ { n = 1 } ^ { \text { Path } } \sum _ { m } ^ { \text { non-default } } \left(\prod_{k=1}^{J_{m}} P_{k}^{\text {Path }} \prod_{k=1}^{J_{m}} e^{\left.\left.-f_{k}^{\text {Path } \mid n} t_{k-1}^{k}\right) C_{m}\right)}\right.\right. \\
I_{\text {Path }}^{\text {df }}=\prod_{n=1}^{J_{m}} P_{b_{(n-1)} \rightarrow b_{n}}^{\text {mig|n }} e^{-f_{n}^{\text {Path } \mid m} t_{n-1}^{n}}
\end{gathered}
$$




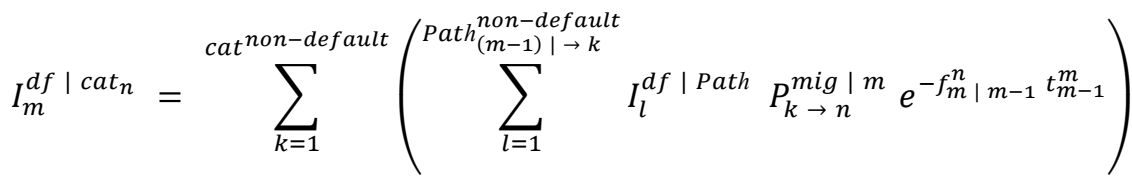

$$
\begin{aligned}
& =\sum_{k=1}^{c a t^{\text {non-default }}} I_{m-1}^{\text {df } \mid c a t_{k}} P_{k \rightarrow n}^{m i g \mid m} e^{-f_{m \mid m-1}^{n} t_{m-1}^{m}} \\
& V=\sum_{m=1}^{M}\left(\sum_{n=1}^{{ }^{c a t}{ }^{\text {non-default }}} I_{J_{m}}^{d f \mid \text { cat }_{n}} C_{m}\right)
\end{aligned}
$$

Equation 6 includes the cash flows gained from recovery of par, after default. The recovery cash flow component is taken from equation 1. Again, $r_{t_{m}}^{r f}$ and $t_{m}$ are the risk-free spot rate and time value, respectively, associated with coupon date $m ; P_{k \rightarrow \text { default }}^{m i g} \mid n$ is the probability of category $k$ migrating to default status in interval $n$.

$$
\begin{aligned}
& V=\sum_{m=1}^{M}\left(\sum_{n=1}^{\text {Path }_{m}^{\text {non-default }}}\left(\prod_{k=1}^{J_{m}} P_{k}^{\text {Path }} e^{-f_{k}^{\text {Path } \mid n} t_{k-1}^{k}} C_{m}\right)\right)+\sum_{m=1}^{J_{M}}\left(\sum_{n=1}^{\text {Path }_{m}^{\text {default }}} \prod_{k=1}^{m} P_{k}^{\text {Path }}{ }^{-r_{t_{m}}^{r f} t_{m}} R\right) \\
& V=\sum_{m=1}^{M} \sum_{n=1}^{{ }^{c a t}{ }^{\text {non-default }}} I_{J_{m}}^{\text {df } \mid \text { cat }_{n}} C_{m}+\sum_{m=1}^{J_{M}}\left(\prod_{n=1}^{m-1}\left(1-h_{n}\right) h_{m} e^{-r_{t_{m}}^{r f} t_{m}} R\right) \\
& V=\sum_{m=1}^{M} \sum_{n=1}^{\text {cat }} I_{J_{m}}^{\text {non-default }}{ }^{\text {cat }_{n}} C_{m}+\sum_{m=1}^{J_{M}} \sum_{n=1}^{\text {cat }} I_{m-1}^{\text {non-default }} P_{n \rightarrow \text { default }}^{\text {mig }} e^{-r_{t_{m}}^{r f}} t_{m} R_{m}^{n}
\end{aligned}
$$

Equation 7 calculates the net change in value at point $m$ due to rating migration over the remaining probability intervals from that point to maturity. It is calculated as the sum of the change in future value for each remaining probability interval, up to maturity, based on rating migration per interval.

$D F_{n \mid m}^{a}$ is the discount factor of rating category $a$ over the interval demarcated by point in time $n$ and $m ; r_{n \mid m}^{a}$ is the forward rate of rating category $a$ over the interval demarcated by point in time $n$ and $m ; r_{n}^{a}$ is the spot rate of rating category $a$ over the interval $n ; r_{t_{m}}^{r f}$ is the risk-free spot rate associated with point in time $m$; $t_{m}^{n}$ is the interval demarcated by point in time $n$ and $m ; F V_{m}^{a}$ is the future value of a bond of rating category $a$, in interval $m ; V_{m}^{a}$ is the value of a bond with bond rating $a$, in interval $m ; \Delta V_{m}^{a} \rightarrow b$ is the change in value of a bond due to a rating migration from rating $a$ to $b$ in interval $m ; \Delta V_{m}^{a}$ is the change in value of a bond with rating category $a$ due to rating migration to any other non-default rating category in interval $m ; I_{m}^{c a t_{n}}$ is the intensity or propensity of rating category $n$ in interval $m ; P_{k \rightarrow n}^{m i g \mid m}$ is the probability of migration from category $k$ to category $n$ in interval $m$; $M$ is the number of coupons of the bond, including par value; $C_{m}$ is the bond coupon corresponding to coupon date $m$; cat $^{\text {non-default }}$ are all non-default rating categories; $P V(x)$ refers to the present value of $x ; R_{m}^{n}$ is the recovery of par value of rating category $n$ in interval $m ; k_{m}$ is the number of coupons remaining at (after) interval $m$.

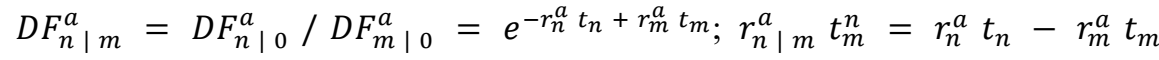

$$
\begin{aligned}
& V_{m}^{a}=F V_{m}^{a}=\sum_{n=k_{m}}^{M} e^{-r_{n \mid m}^{a} t_{m}^{n}} C_{n}
\end{aligned}
$$




$$
\begin{gathered}
\Delta V_{m}^{a} \rightarrow b=F V_{m}^{a}-F V_{m}^{b}=V_{m}^{a}-V_{m}^{b} \\
\Delta V_{m}^{a} \rightarrow b=\sum_{n=k_{m}}^{M} e^{-r_{n \mid m}^{a} t_{m}^{n}} C_{n}-\sum_{n=k_{m}}^{M} e^{-r_{n \mid m}^{b} t_{m}^{n}} C_{n}=\sum_{n=k_{m}}^{M}\left(e^{-r_{n \mid m}^{a} t_{m}^{n}}-e^{-r_{n \mid m}^{b} t_{m}^{n}}\right) C_{n} \\
\Delta V_{m}^{a}=\sum_{b=1}^{c a t^{n o n-d e f a u l t}} I_{J_{m}-1}^{c a t_{a}} P_{a \rightarrow b}^{m i g \mid J_{m}} \Delta V_{m}^{a} \rightarrow b=\sum_{b=1}^{c a t^{n o n-d e f a u l t}} I_{m-1}^{c a t_{a}} P_{a \rightarrow b}^{m i g \mid m} \sum_{n=k_{m}}^{M}\left(e^{-r_{n \mid m}^{a} t_{m}^{n}}-e^{-r_{n \mid m}^{b} t_{m}^{n}}\right) C_{n} \\
\Delta V_{m}=\sum_{n=j_{m}+1}^{J_{M}} \sum_{k=1}^{c a t^{n o n-d e f a u l t}} P V\left(\Delta V_{n}^{k}\right)=\sum_{n=j_{m}+1}^{J_{M}} \sum_{k=1}^{c a t^{n o n-d e f a u l t}} \Delta V_{n}^{k} e^{-r_{t_{m}}^{r f} t_{m}}
\end{gathered}
$$

Equation 8 states the value of a bond as the present value of coupons received up to future point $w$, plus the present value of the future value of the bond at point $w$; point $w$ is before maturity. In essence, it states the value of the bond when the bond is not kept to maturity, but sold before maturity. Equation 8.2 states the future value of the bond according to the present value of coupons to be received after point $w$ (equation 3). Equation 8.3 states the future value according to the present value of the future paths of the bond after point $w$ (equation 6). Equation 8.4 states the future value as the sum of the value of the remaining bond coupons at time $w$, discounted against the rating categories' future rates at point $w$, and weighed according to the rating categories' propensities at point $w$ - for each rating category, its propensity is considered at point $w$, and all remaining coupons are discounted against the future rates of the rating category at point $w$. Again, some similarity and convergence is expected among the equations - the equations should produce similar results. For equation 8.3 to equal equation 6 , the future value of the bond is not discounted to present value by the risk-free rate, but by the rating path based spot rate $R_{t_{w}}^{n}$.

$C_{m}$ is the coupon of the bond on coupon date $m ; k_{w}$ is the number of coupons up to point $w ; R_{m}^{n}$ is the recovery of par value of rating category $n$ in interval $m ; P_{m}$ is the cumulative non-default probability of interval $m ; r_{t_{m}}^{r f}$ and $t_{m}$ are the risk-free spot rate and time value, respectively, associated with coupon date $m ; r_{t_{w}^{m}}^{r f}$ is the risk-free forward rate over the interval $(w, m)-t_{w}^{m} ; r_{t_{w}^{m}}^{n}$ is the risk-bearing forward rate of rating category $n$ over the interval $(w, m)$; $I_{m}^{c a t_{n}}$ is the intensity or propensity of rating category $n$ in interval $m ; I_{m}^{d f \mid c a t_{n}}$ is the forward rate based intensity or propensity of rating category $n$ in interval $m ; I_{m \mid w}^{c a t_{n}}$ is the intensity or propensity of rating category $n$ in interval $m$, measured from point $w ; I_{m \mid w}^{d f \mid c a t_{n}}$ is the forward rate based intensity or propensity of rating category $n$ in interval $m$, measured from point $w ; P_{k \rightarrow \text { default }}^{\text {mig } \mid m}$ is the probability of migration from category $k$ to default in interval $m ; P V(x)$ refers to the present value of $x ; F V_{w}$ refers to the future value of the bond at point $w ; J_{m}$ is the number of probability intervals considered up to coupon date $m ; R_{t_{w}}^{n}$ is the risk-bearing rating path based spot rate of rating category $n$ for point $w$.

$$
V=\sum_{m=1}^{k_{w}} P_{m} e^{-r_{t_{m}}^{r f} t_{m}} C_{m}+\sum_{j=1}^{J_{w}} \sum_{n=1}^{\text {cat }} I_{j-1}^{\text {non-default }} P_{n \rightarrow \text { default }}^{\text {mig } j} e^{-r_{t_{j}}^{r f} t_{j}} R_{j}^{n}+P V\left(F V_{w}\right)
$$




$$
\begin{aligned}
& P V\left(F V_{w}\right)=e^{-r_{t_{w}}^{r f} t_{w}}\left(\sum_{m=k_{w}+1}^{M} P_{m} e^{-r_{t_{w}^{m}}^{r f} t_{w}^{m}} C_{m}+\sum_{j=J_{w}+1}^{J_{M}} \sum_{n=1}^{\text {cat }} \sum_{j-1}^{\text {non-default }} P_{n \rightarrow \text { default }}^{\text {mig } e^{j} t^{-r_{w}^{r f}} t_{w}^{j} R_{j}^{n}}\right) \\
& P V\left(F V_{w}\right)=\sum_{m=k_{w}+1}^{M} \sum_{n=1}^{\text {cat }} I_{J_{m} \mid w}^{\text {nfon-default }} e^{-R_{t_{w}}^{n} t_{w}} C_{m} \\
& +\left(\sum_{m=J_{w}+1}^{J_{M}} \sum_{n=1}^{\text {cat }} I_{m-1}^{\text {non-default }} P_{n \rightarrow \text { default }}^{\text {mig } \mid m} e^{-r_{t_{w}^{m}}^{r f} t_{w}^{m}} R_{m}^{n}\right) e^{-r_{t_{w}}^{r f} t_{w}} \\
& I_{m}^{d f \mid c a t_{n}}=I_{m}^{c a t_{n}} e^{-R_{t_{m}}^{n} t_{m}} \\
& P V\left(F V_{w}\right)=e^{-r_{t_{w}}^{r f} t_{w}}\left(\sum_{m=k_{w}+1}^{M} \sum_{n=1}^{\text {cat }} I_{J_{w}}^{c a t_{n}} e^{-r_{t_{w}^{m}}^{n} t_{w}^{m}} C_{m}\right)
\end{aligned}
$$

\subsubsection{Term Structure Volatility and Term Structure Volatility Premiums}

At some point, one or more of the equations above reference the recovery of par, the risk-free rate, risk-bearing rates, and a rating migration matrix as input. The recovery of par, the risk-free rate as term structure, the risk-bearing rate as term structure, and the rating migration matrix can all carry additional volatility as uncertainty. All but uncertainty pertaining to recovery of par is discussed next.

Term structure stability (Marciniak, 2006) is a well-known factor with regards to term structure decomposition, and term structure volatility - variance over term structures pertaining to similar points in time, decomposed at different dates - is also documented (Marciniak, 2006). If the ahistorical risk-free and risk-bearing term structures are accepted as volatile, it should not be difficult to also consider ahistorical rating migration as volatile - that the probability of rating migration to both non-default credit ratings as well as default, is ahistorically uncertain.

Two views can be taken regarding term structure volatility: i) premiums for term structure volatility are already included in term structure spot rates, such that cash flows that reference these rates are already guarded against term structure volatility; ii) premiums for term structure volatility should be added as additional factors of a bond valuation model. Below, options are used to demonstrate the cost of term structure volatility, and options manage to do this quite intuitively. At the same time, the magnitude (cost) of the options may be negligible, suggesting that premiums for term structure volatility are already included in spot rates.

A basic premise of the view that term structure volatility premiums are already included, is that continuously or repetitively rolling over short term investments - investing and re-investing when the investment term expires - in risk-free and risk-bearing bonds should not yield higher returns than a single, long-term investment in the same security type, for the same investment term. As illustration, consider reinvesting in the next bond with 1 year to maturity, when the previous investment expires, and doing so for a period of 5 years, versus investing in a bond with 5 years to maturity. Here, continuously investing and reinvesting in bonds with short time to maturities has the advantage that long term term structure uncertainty is avoided, and market rates at the applicable points in time are likely more reflective of term structure rates at that point. The long-term bond must yield a return at least the same as the repetitive short-term investment, merely to be appropriate in terms of compensation in light of economic conditions. Yet, because it entails more uncertainty, the long-term investment is expected to yield a higher return - only under ideal market efficiency would it yield a similar return than the short term investment.

This highlights the dichotomy between historical and ahistorical, and points out that historical estimates may find it difficult to fully account for and explain ahistorical prices. As long as the long-term investment yields an appropriately higher return than the short-term investment, term structure volatility premiums are likely already included in term structure spot rates. In the above, appropriately higher implies what is humanly possible under practical levels of market efficiency.

In the case that term structure volatility premiums are already included in spot rates, bond valuation models may only be able to examine and state the magnitude of such premiums via i) ahistorical estimates of term structure volatility - or historical estimates as approximation thereof - or ii) isolating the term structure volatility component from the spread 
between the short-term and long-term investment.

To further the second view that term structure volatility premiums should still be included, the vantage point is taken that a risk-bearing bond would approximate a risk-free bond, if all of its cash flows were made certain. This does not necessarily imply that default should be prevented, or can not be allowed to occur; rather that default must be made certain. With reference to the above equations, the elements to fix would be the risk-free and risk-bearing term structures, as well as the applicable rating migration matrix. If these elements were certain, the cash flows - and value thereof - of risk-bearing bonds would be as certain as the cash flows of risk-free bonds. Here, options are the method by which the cash flows are made certain.

With regards to risk-free term structure volatility, the recovery of par especially depends on the certainty of the risk-free rate, even if it is depicted as a term structure. The basic reduced form valuation model of equation 1 is also heavily dependent on the certainty of the risk-free rate - from the vantage point of these equations, ordinary promised coupons are dependent on the certainty of the risk-free rate. If market consensus regarding the applicable ahistorical risk-free rate worsens, all cash flows that build on it - recovery cash flows, for example - are worth less than anticipated. It may also render the investor sensitive to the investment period. The cost to guarantee risk-free rate dependent cash flows is seen as proportional to the cost of a future contract option to receive 100 currency at a future date, when paying the present value of 100 currency, based on the current risk-free term structure, now. The weight of the premium is taken to be related to the probability of the underlying cash flow, though this is a hypothetical or ideal stipulation. In practice, it is not truly known which of the bonds in the portfolio would follow certain paths, only the likely paths the bonds would follow. Hence, the options can not be taken for a proportion of the bonds only, but must be taken for all bonds. The magnitude of the price of the option should indicate the need for a premium to guarantee cash flows dependent on the risk-free rate.

Equation 9.1 and 9.3 depict the premium to guarantee the value of recovery and coupons against risk-free term structure volatility, respectively. Equation 9.2 and 9.4 weight the premiums according to the probability of occurrence. Equation 9.5 adds a premium to the basic reduced form model of equation 3, to guarantee the value of recovery and coupons against risk-free term structure volatility. $R_{m}^{n}$ is the recovery of par value of rating category $n$ in interval $m$; $C_{m}$ is the bond coupon corresponding to coupon date $m ; M$ is the number of coupons, including par; $U_{r f}^{R \mid m}$ is the premium to guarantee the value of recovery of par expected in interval $m$ against risk-free term structure volatility; $U_{r f}^{C \mid m}$ is the premium to guarantee coupon $C$ expected in interval $m$ against risk-free term structure volatility; $\widetilde{U}_{r f}^{R \mid m}$ and $\widetilde{U}_{r f}^{C \mid m}$ is the premium $U_{r f}^{R \mid m}$ and $U_{r f}^{C \mid m}$ weighted according to their probability of occurrence, respectively; $\left.F_{P V_{0}^{r f}(100)}^{100}\right|_{m} ^{r f}$ is a futures option to receive 100 currency at future point in time $m$ for the current or immediate payment that equals its present value $P V_{0}^{r f}(100)$ according to the present risk-free term structure; $P_{m}^{n}$ is the cumulative non-default probability of rating category $n$ in interval $m ; I_{m}^{c a t_{n}}$ is the intensity or propensity of rating category $n$ in interval $m ; P_{k \rightarrow \text { default }}^{m i g \mid n}$ is the probability of category $k$ migrating to default status in interval $n$.

$$
\begin{gathered}
U_{r f}^{R \mid m}=\left(R_{m}^{n} / 100\right) \cdot F_{P V_{0}^{r f}(100)}^{100 \mid m} \\
\widetilde{U}_{r f}^{R \mid m}=\sum_{n=1}^{{ }^{\text {cat }}{ }^{\text {non-default }}} I_{J_{m}-1}^{\text {cat } t_{n}} P_{n \rightarrow \text { default }}^{\text {mig } \mid J_{m}} U_{r f}^{R \mid m} \\
U_{r f}^{C \mid m}=\left(C_{m} / 100\right) \cdot F_{P V_{0}^{r f}(100)}^{100 \mid m}
\end{gathered}
$$




$$
\begin{gathered}
\widetilde{U}_{r f}^{C \mid m}=P_{m} U_{r f}^{R \mid m} \\
V=\sum_{m=1}^{M} P_{m} e^{-r_{t_{m}}^{r f} t_{m}} C_{m}+\sum_{j=1}^{J_{M}} \sum_{n=1}^{c a t^{n o n-d e f a u l t}} I_{j-1}^{\text {cat }} P_{n \rightarrow \text { default }}^{\text {mig } j} e^{-r_{t_{j}}^{r f} t_{j}} R_{j}^{n}-\sum_{m=1}^{M} \widetilde{U}_{r f}^{C \mid m}-\sum_{m=1}^{J_{M}} \widetilde{U}_{r f}^{R \mid m}
\end{gathered}
$$

Cash flows or valuations that depend on risk-bearing rates as term structures can be secured in a similar manner. The equations above (equation 5 - 6) that stipulate the value of a bond according to its likely rating paths, utilize and are sensitive to risk-bearing term structures. Put options to sell a bond at a particular future point in time at its future value, according to the present risk-bearing term structure corresponding to the bond's expected credit rating at the future point in time, can help to guarantee the future value of a bond with a particular rating at that point. This guarantees the value of the bond calculated according to its likely rating paths ${ }^{1}$.

Equation 10.1 depicts the premium to guarantee the value of a risk-bearing bond against risk-bearing term structure volatility. Equation 10.2 and 10.3 weight the premium according to the probability of occurrence. For the same reasons mentioned before, the weights are hypothetical or ideal. Equation 10.4 adds a premium to equation 8.1 and 8.4 to guarantee the future value of the bond against risk-bearing term structure volatility.

$P V(x)$ refers to the present value of $x$, discounted against the risk-free term structure; $U_{R \mid a}^{B \mid m}$ is the premium to guarantee the value of a risk-bearing bond $B$ with rating category $a$ at point in time $m$ against risk-bearing term structure volatility; $O_{F V_{0}^{a}(B) \mid m}^{B \mid p u t}$ is a put option to sell a risk-bearing bond $B$ with expected rating category a at future point in time $m$, at its future value $F V_{0}^{a}(B)$ according to the present, applicable risk-bearing term structure of rating category $a ; \widetilde{U}_{R \mid a}^{B \mid m}$ is the premium to guarantee the future value of a risk-bearing bond that will have credit rating $a$ in interval $m$, weighted according to its probability of occurrence; $\widetilde{U}_{R}^{B \mid m}$ is the cumulative premium to guarantee all bond future values in interval $m ; P_{m}$ is the cumulative non-default probability of interval $m ; I_{m}^{c a t_{n}}$ is the intensity or propensity of rating category $n$ in interval $m ; P_{k \rightarrow \text { default }}^{m i g \mid n}$ is the probability of category $k$ migrating to default status in interval $n ; C_{m}$ is the bond coupon corresponding to coupon date $m ; M$ is the number of coupons, including par; $R_{m}^{n}$ is the recovery of par value of rating category $n$ in interval $m$.

$$
\begin{aligned}
& U_{R \mid a}^{B \mid m}=O_{F V_{0}^{a}(B) \mid m}^{B \mid p u t} \\
& \widetilde{U}_{R \mid a}^{B \mid m}=I_{J_{m}}^{c a t a} O_{F V_{0}^{a}(B) \mid m}^{B \mid p u t} \\
& \widetilde{U}_{R}^{B \mid m}=\sum_{k=1}^{\text {cat non-default }} \widetilde{U}_{R \mid k}^{B \mid m}=\sum_{k=1}^{\text {cat }} \sum_{J_{m}^{\text {non-default }}}^{\text {cat }_{k}} O_{F V_{0}^{k}(B) \mid m}^{B \mid \text { ut }} \\
& V=\sum_{m=1}^{k_{w}} P_{m} e^{-r_{t_{m}}^{r f} t_{m}} C_{m}+\sum_{j=1}^{J_{w}} \sum_{n=1}^{\text {cat }} I_{j-1}^{\text {non-default }} P_{n \rightarrow \text { default }}^{\text {mig } \mid j} e^{-r_{t_{j}}^{r f} t_{j}} R_{j}^{n}+P V\left(F V_{w}\right)-\widetilde{U}_{R}^{B \mid w}
\end{aligned}
$$

Similarly, put options and call options can be used to guarantee credit rating migration probability between non-default categories; the intricacies thereof will not be stated here though. Put options reflect the premium to guard against more credit quality degradation than anticipated. The put option is stipulated to sell a bond at a future value in a particular

1 Similarly specified call options would further help to balance the premium. 
interval, according to the term structure of the anticipated credit rating in that interval, and will be in value when the bond realized a lower credit rating in the interval. Call options reflect the excess due to less credit quality degradation than anticipated, and help to balance the overall premium due to credit migration volatility. The call option is stipulated to buy a bond at a future value in a particular interval, according to the term structure of the anticipated credit rating in that interval, and will be in value when the bond realized a higher credit rating in the interval. Both options are weighted according to the probability of the bond, with initial credit rating $a$, reaching an anticipated rating $b$ in interval $m$, but this is ideal.

The drawback of this approach is that it does not guard against unanticipated rating migration that actually leads to default - higher than expected default rates for one or more rating categories. In light of this, a more balanced approach may be to assume as applicable, a rating migration matrix with higher volatility - measured as the cumulative probability of migrating out of a particular rating category to another category or to default. This will simultaneously allow a higher rate of default per category, higher probability of non-default rating migration, and preserve migration probability integrity.

Hence, the basic argument is that rating migration uncertainty - also from a bond valuation premium perspective - may be best addressed through a more volatile rating migration matrix. Also, evident of risk-bearing term structure uncertainty is that it may predominantly relate to rating migration uncertainty. Given the relationship that should hold between the value of a bond as expected cash flows discounted against default probability (equation 3), and the value of a bond as the value of future rating migration paths (equation 8), and if market risk-bearing spot rates already include premiums for rating migration uncertainty, it likely is done through more volatile rating migration matrices, compared to historical rating migration matrices. This again stresses the dichotomy between ahistorical and historical estimates rating migration matrices in particular.

\subsubsection{Tax Premiums}

Equation set 11 adds a tax premium to equation 3. Because of similarity in application, it is not repeated for the other equations as well. $T$ is the tax rate.

$$
V=\sum_{m=1}^{M} P_{m} e^{-r_{t_{m}}^{r f} t_{m}} C_{m}(1-T)+\sum_{j=1}^{J_{M}} \sum_{n=1}^{\text {cat }} I_{j-1}^{\text {non-default }} P_{n \rightarrow \text { default }}^{\text {mig } j j} e^{-r_{t_{j}}^{r f} t_{j}} R_{j}^{n}
$$

\subsubsection{Decomposing Market Rating Migration Probabilities}

What should be evident from the reduced form models above, is that it is indeed possible to extract ahistorical rating migration probability matrices from market prices. The valuation models above can be used to model bond value, and this is optimized against market prices via the ahistorical rating migration matrix being decomposed. The accuracy and validity of the rating migration matrix decomposed would depend on the comprehensiveness of the valuation model used to model bond value.

Equation set 12 contains the optimization problem to extract the market rating migration matrix from market prices. Any proper rating migration matrix that satisfy the constraints could serve as initial solution. The probabilities of the migration matrix are adjusted and selected as part of the optimization. A number of constraints are stipulated: For each rating category, the sum of the probabilities of migrating from the particular category to any other non-default category, plus the probability of default of the category should equal 1 (equation 12.b). For each rating category, any probability of migrating to any other non-default category, as well as the probability of default of that particular category should be greater than or equal to zero (equation 12.c). For each rating category with a category preceding it, the particular category's probability of default should be equal to or higher than that of the category preceding it (equation 12.d). For each rating category, the probability of migrating to rating category $n$ is equal to or greater than the probability of migrating to rating category $n+1$ (equation 12.e).

$V_{n}^{\text {market }}$ and $V_{n}^{\text {model }}$ are the market and modelled bond value of bond $n ; V_{n}^{\text {market } \mid k}$ and $V_{n}^{\text {model } \mid k}$ are the market and modelled bond value of bond $n$ with rating category $k ; N$ is the total number of bonds included in the sample; $N_{k}$ is the total number of sample bonds of rating category $k$; cat non-default refers to all the non-default rating categories; $P_{m \rightarrow n}^{m i g}$ is the probability of migrating from category $m$ to $n ; P_{c a t}^{\text {default }}$ is the probability of default for category $m$.

$$
\operatorname{minimize} \sum_{n=1}^{N}\left(V_{n}^{\text {market }}-V_{n}^{\text {model }}\right)^{2}
$$




$$
\text { minimize } \sum_{k=1}^{\text {cat }} \sum_{n=1}^{\text {non-default }}\left(V_{n}^{\text {market } \mid k}-V_{n}^{\text {model } \mid k}\right)^{2}
$$

Subject to:

$$
\begin{aligned}
& \sum_{n=1}^{\text {cat }^{\text {non- default }}} P_{m \rightarrow n}^{\text {mig }}+P_{\text {cat }_{m}}^{\text {default }}=1 ; m \in\left\{1, \ldots, c a t^{\text {non-default }}\right\} \\
& \sum_{n=1}^{\text {cat }_{\text {non- default }}} P_{m \rightarrow n}^{\text {mig }} \geq 0 \quad P_{\text {cat }_{m}}^{\text {default }} \geq 0 ; m \in\left\{1, \ldots, \text { cat }^{\text {non-default }}\right\} \\
& P_{\text {cat }_{m}}^{\text {default }} \geq P_{\text {cat }_{m-1}}^{\text {default }} ; m \in\left\{2, . ., \text { cat }^{\text {non-default }}\right\} \\
& P_{n \rightarrow n-x}^{\operatorname{mig}} \geq P_{n \rightarrow n-x-1}^{m i g} \\
& n \in\left(1, \ldots c a t^{\text {non-default }}\right) \\
& P_{n \rightarrow n+x}^{m i g} \geq P_{n \rightarrow n+x+1}^{m i g} \\
& n-x \leq \text { cat }^{\text {non-default }} ; n-x-1 \geq 1 \\
& n+x+1 \leq \text { cat }^{\text {non-default }} ; n+x \geq 1
\end{aligned}
$$

\subsubsection{Liquidity Premiums}

Market risk-bearing spot rates should carry liquidity premiums. In this case, liquidity should be a function of credit quality (rating), over and above conventional liquidity proxies (issued amount, listed, currency-denomination, on-the-run, age, missing prices, yield volatility, number of contributors and yield dispersion - Houweling et al, 2005) depending on the demand-characteristics of lower credit quality bonds, such bonds may experience a greater liquidity premium, compared to higher credit quality bonds. This may relate to the frequently used notion of flight-to-quality.

\subsubsection{Credit Default Swaps}

Equation 13 states the present value of all future CDS payments equal to the present value of payments in the case of default. It is assumed that risk-free term structure volatility premiums are already included in the risk-free rate. $P^{c d s}$ is the contractual CDS payments; $L$ is the number of payments within the period of the contract; $P A R$ is the par value of the bond; $R_{m}^{n}$ is the recovery of par value of rating category $n$ in interval $m ; P_{k \rightarrow \text { default }}^{\text {mig } n}$ is the probability of category $k$ migrating to default status in interval $n ; P_{m}$ is the cumulative non-default probability of interval $m$; $P_{m}^{n}$ is the cumulative non-default probability of rating category $n$ in interval $m$; cat ${ }^{\text {non-default }}$ are all non-default rating categories; $r_{t_{m}}^{r f}$ is the risk-free spot rate associated with point in time $m$.

$$
\sum_{m=1}^{L} P_{m} e^{-r_{t_{m}}^{r f} t_{m}} P^{c d s}=\sum_{m=1}^{J_{M}} \sum_{n=1}^{c a t^{\text {non-default }}} I_{m-1}^{\text {cat }} P_{n \rightarrow \text { default }}^{\text {mig } \mid m} e^{-r_{t_{m}}^{r f} t_{m}}\left(P A R-R_{m}^{n}\right)
$$

\subsubsection{Concluding Remarks}

A great emphasis of this section was the use of rating migration probabilities to obtain default probabilities. Also, bonds were valued according to their likely future ratings. Term structure uncertainty was also briefly considered.

There is little to support the belief that ahistorical estimates should correspond with historical estimates. Ahistorical estimates are normally expected to be higher than historical estimates. This is also true for rating migration and default probabilities. Ahistorical rating migration matrices can be extracted from market prices, and it is expected to be more volatile than historical rating migration matrices, simply because uncertainty is removed from the latter. It is equally as difficult to believe that the market exclusively and solely consider historical rating migration matrices when valuing bonds ahistorically.

The equations above extensively utilize credit ratings as measure or rating of credit quality. It thus refocuses attention 
on credit rating accuracy and timeliness. It may also again stir up interest in credit rating substitutes or alternatives that categorize bonds according to credit quality independent of or different than credit rating agencies.

\section{Methodology}

The scope of the study is limited to reflecting on i) the propagation of bonds with different ratings, as implied by a rating migration matrix (equation 2), ii) the change in value, when expanding the recovery of par according to the rating upon default (equation 3), iii) the net change in future value due to rating migration (equation 7), and iv) valuing a bond according to its likely rating paths (equation 6).

To evaluate equation 6 and 7, a bond is simulated by expanding a standard coupon and par over regular (bi-annual) coupon intervals, from 6 months to 10 years, calculating the value of the bond, and converting it to a yield rate. A standard coupon of 7.5 is used.

For a number of reasons, the study utilizes the data from previous studies to examine the valuation equations. The risk-free and risk-bearing term structures are from Elton et al (2001) and Huang and Huang (2012). The forward rates required for equation 6 are extracted from these term structures. The rating migration matrix and recovery rates are from Elton et al (2001). Seven principal credit ratings are considered - [AAA, AA, A, BBB, BB, B, C].

Table 1 and 2 show the recovery rates and rating migration matrices utilized, respectively. Figure 1 shows the risk-free and risk-bearing term structures ${ }^{2}$. Figure 2 and 3 show the corresponding forward rates, referenced against the spot rate term structures.

Table 1. Recovery rates as percentage of par (Elton et al, 2001)

\begin{tabular}{lllllll}
\hline AAA & AA & A & BBB & BB & B & CCC \\
\hline 68.34 & 59.59 & 60.63 & 49.42 & 39.05 & 37.54 & 38.02 \\
\hline
\end{tabular}

Table 2. Rating migration probability - Standard and Poor's (Elton et al, 2001)

\begin{tabular}{lllllllll}
\hline & AAA & AA & A & BBB & BB & B & CCC & Default \\
\hline AAA & 90.788 & 8.291 & 0.716 & 0.102 & 0.102 & 0.000 & 0.000 & 0.000 \\
AA & 0.103 & 91.219 & 7.851 & 0.620 & 0.103 & 0.103 & 0.000 & 0.000 \\
A & 0.924 & 2.361 & 90.041 & 5.441 & 0.719 & 0.308 & 0.103 & 0.103 \\
BBB & 0.000 & 0.318 & 5.938 & 86.947 & 5.302 & 1.166 & 0.117 & 0.212 \\
BB & 0.000 & 0.110 & 0.659 & 7.692 & 80.549 & 8.791 & 0.989 & 1.209 \\
B & 0.000 & 0.114 & 0.227 & 0.454 & 6.470 & 82.747 & 4.086 & 5.902 \\
CCC & 0.228 & 0.000 & 0.228 & 1.251 & 2.275 & 12.856 & 60.637 & 22.526 \\
Default & 0.000 & 0.000 & 0.000 & 0.000 & 0.000 & 0.000 & 0.000 & 100.000 \\
\hline
\end{tabular}

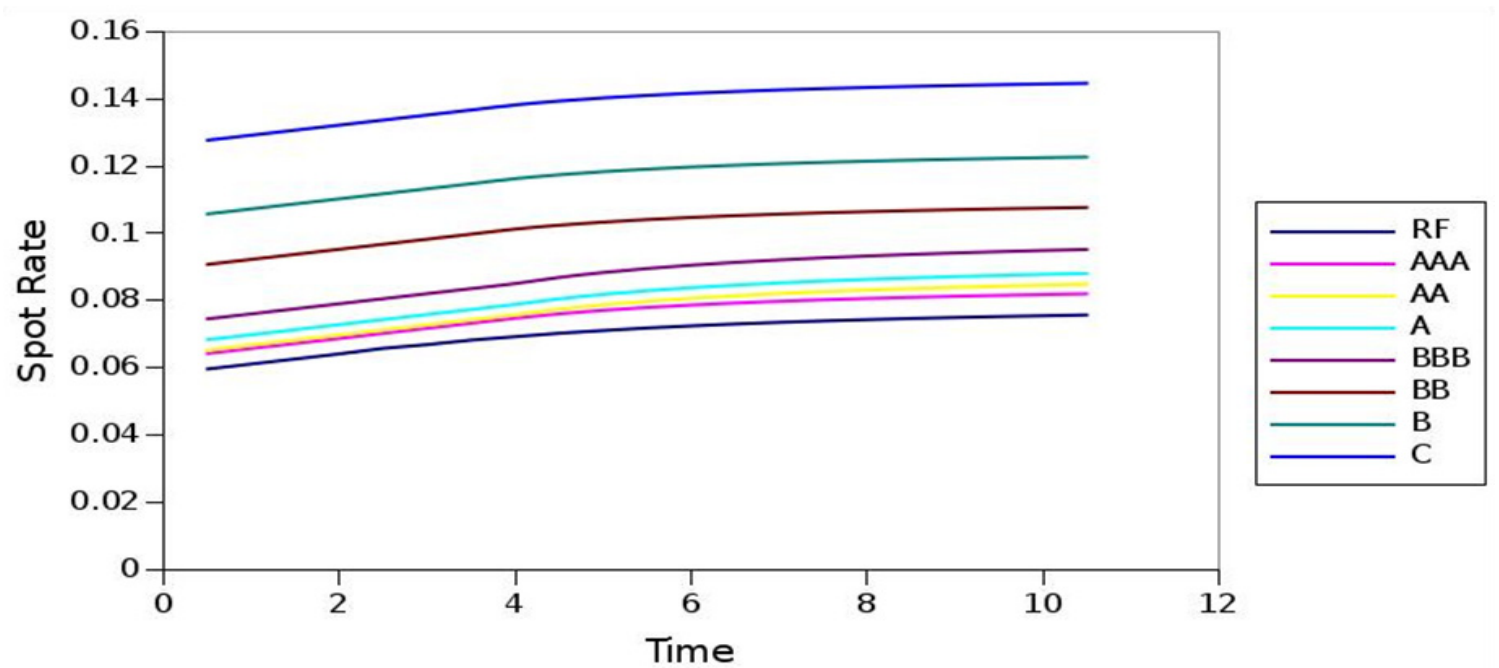

Figure 1. Risk-free and risk-bearing term structures

2 With regards to the legends of Figure 1, RF implies risk-free. 


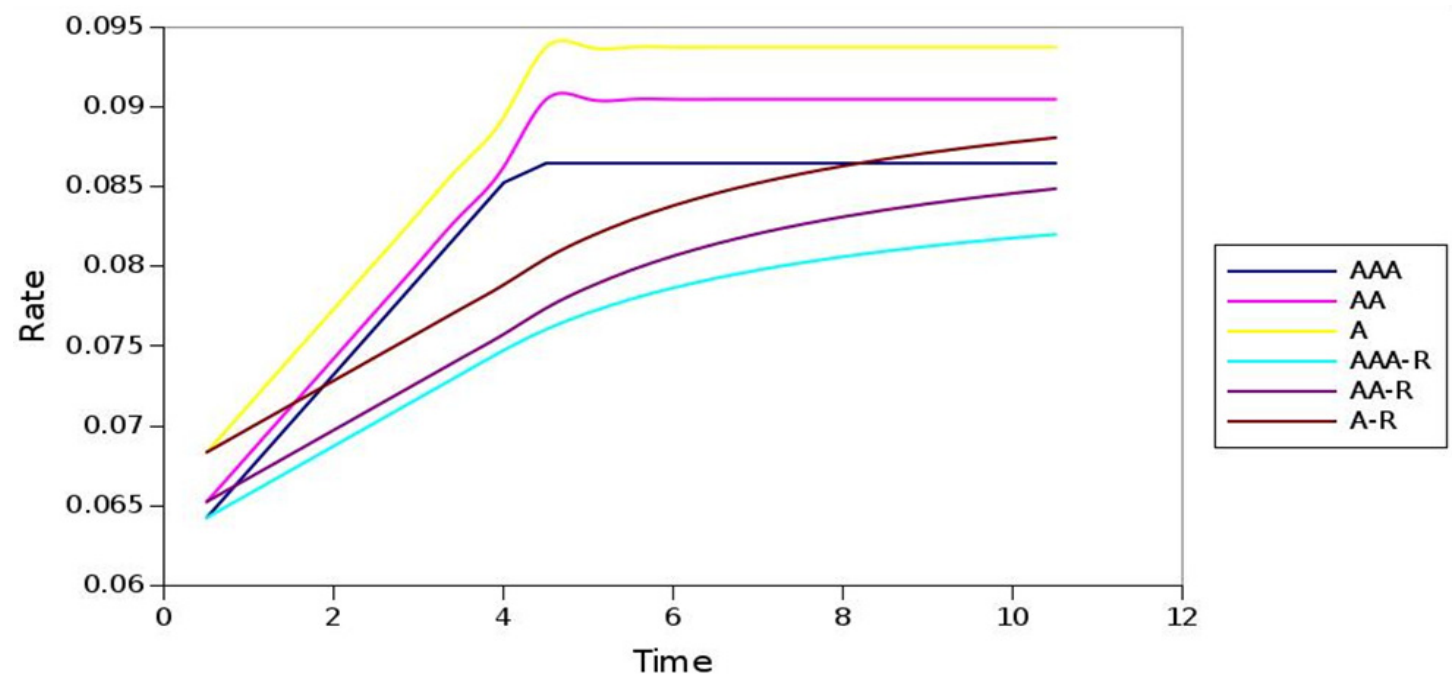

Figure 2. Risk-free and risk-bearing term structure forward rates
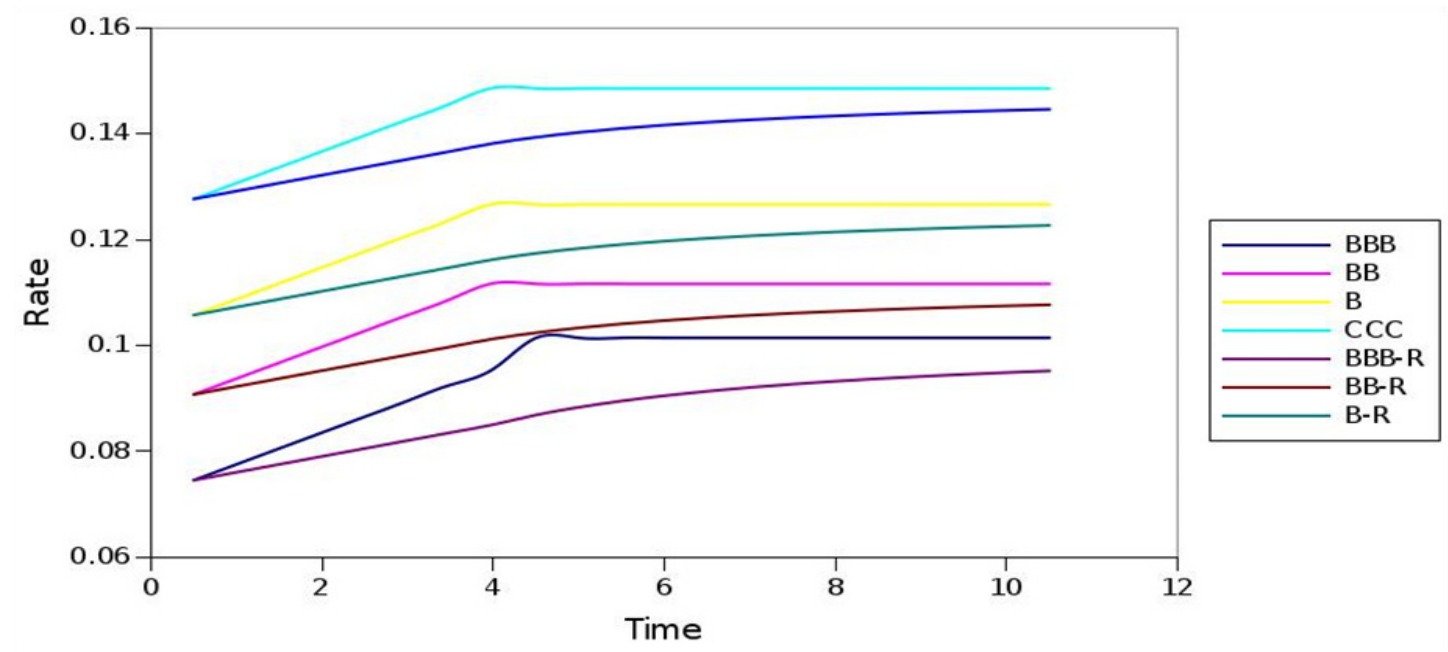

Figure 3. Risk-free and risk-bearing term structure forward rates

\section{Analysis}

Figure 4 to 6 show the interval (yearly) default probability $h_{n}$, cumulative default probability product $\sum_{m=1}^{n-1}\left(1-h_{m}\right) h_{n}$, and

cumulative non-default probability $\sum_{m=1}^{M}\left(1-h_{m}\right)$, respectively. Figure 7 to 13 show the propensity $I_{m}^{c a t_{n}}$ of the rating categories over the intervals, when starting with a purely homogeneous rating category bond portfolio. Figure 7, 8, 9, 10, 11, 12, 13 correspond to a homogeneous bond portfolio with rating category AAA, AA, A, BBB, BB, B, CCC, respectively.

Figure 4 to 13 should demonstrate the significance and impact - the footprint - of rating migration probabilities - the rating migration matrix. These figures also depict the non-linear relationship between credit rating and credit quality. Figure 7 to 13 show that the rating migration matrix has a distinct influence on the quantity and quality of bonds remaining per interval. Figure 4 to 13 should also convey that default probability processes are dynamic and complex. In light of this, is questioned whether it would be possible to reflect on the implications of a rating migration matrix without simulation. Furthermore, the timeline of default may perhaps be split into two distinct cases: i) default as a rapid, unexpected case (AAA rated bonds defaulting, for example), versus ii) default as a prolonged process of worsening credit quality, manifested by a slow, but continued migration to lower ratings. Evidently, default probability is dependent on time, and the dependency differs across the different rating categories. 

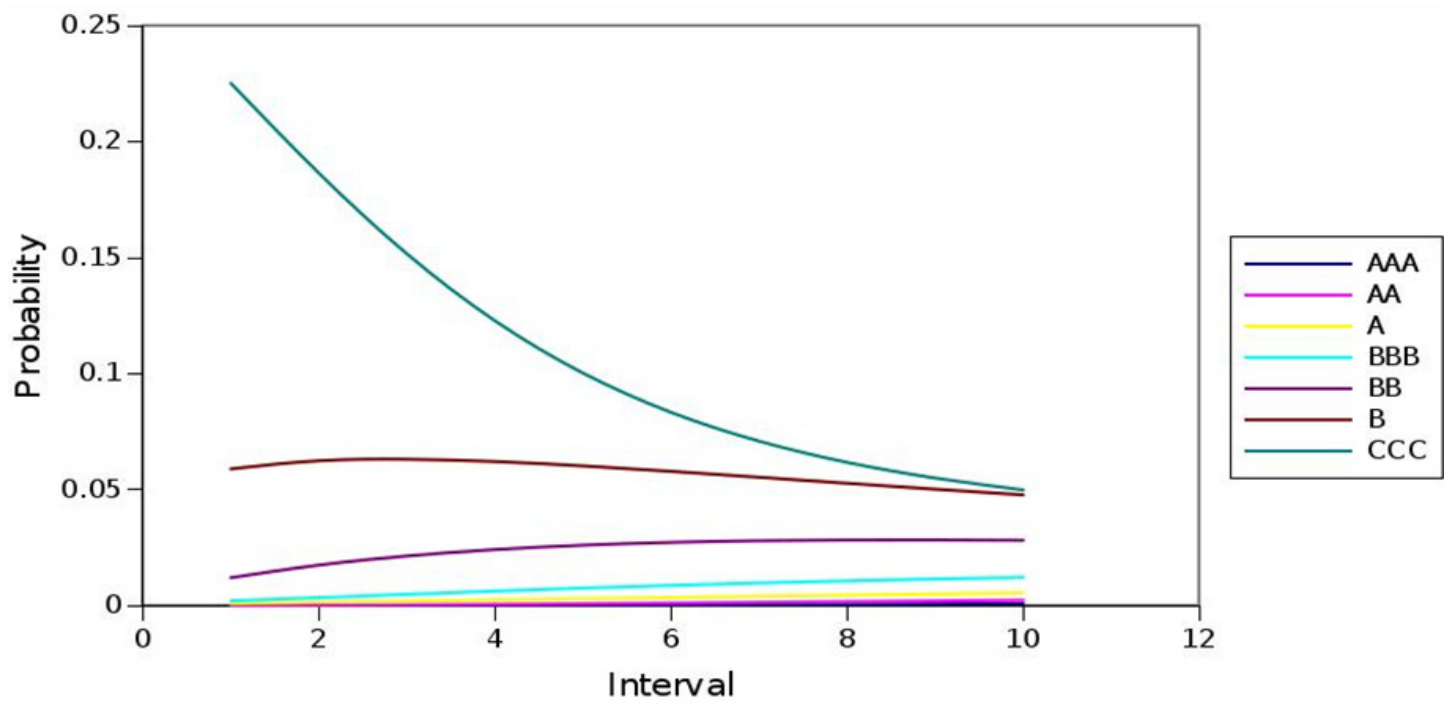

Figure 4. Interval default probability
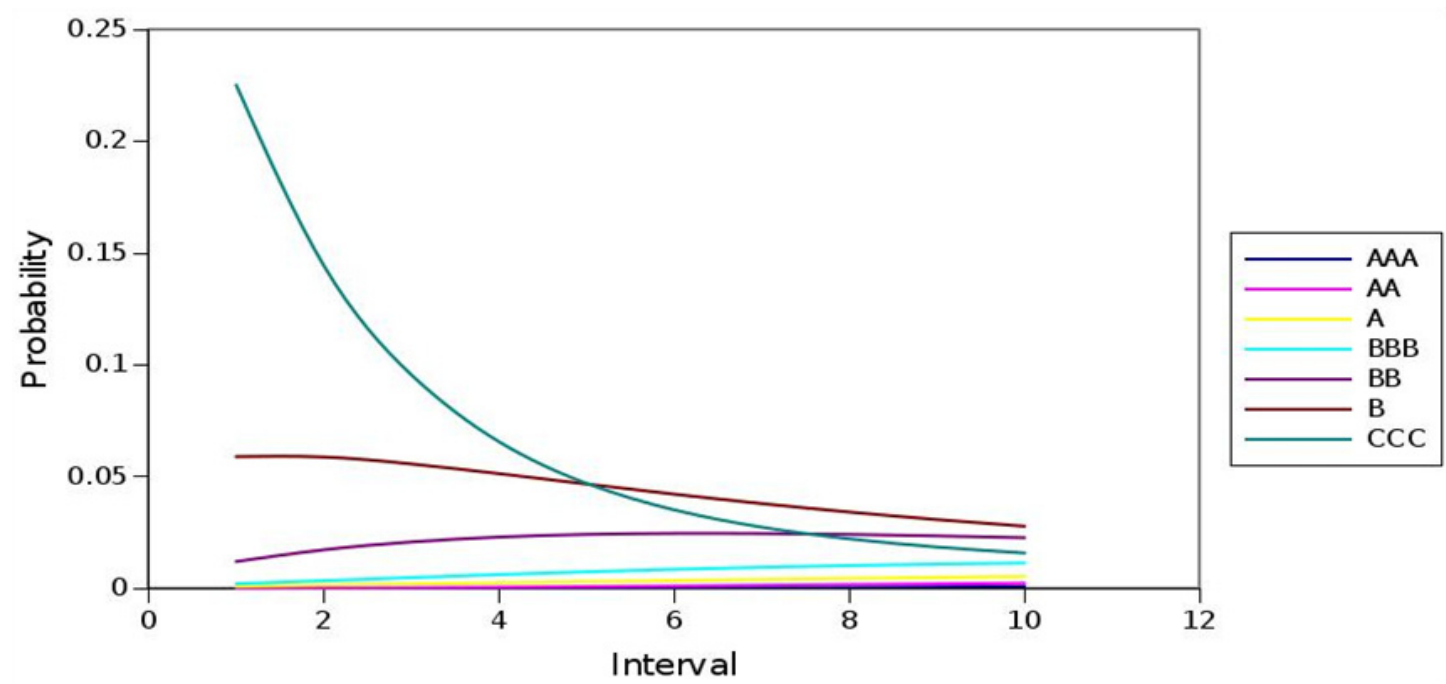

Figure 5. Interval cumulative default probability product
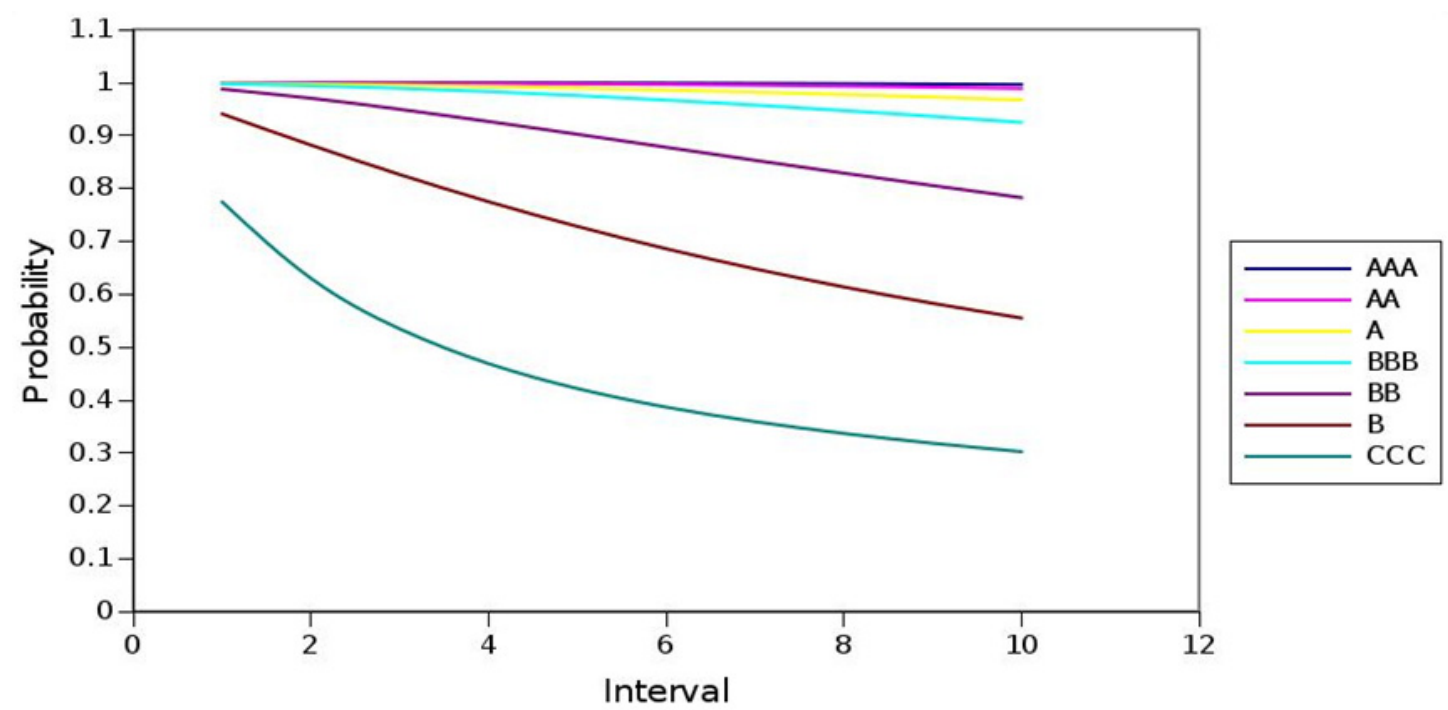

Figure 6. Interval cumulative non-default probability 


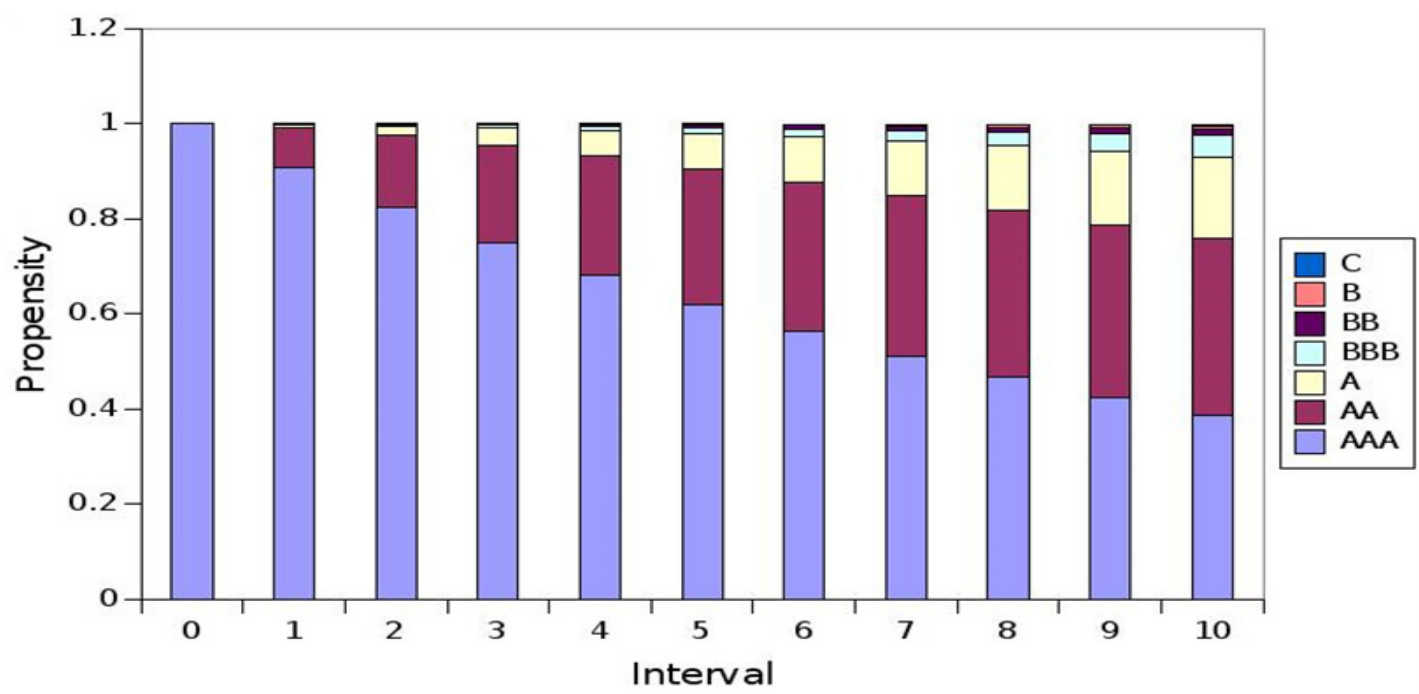

Figure 7. Interval propensity of a homogeneous portfolio with initial rating: AAA

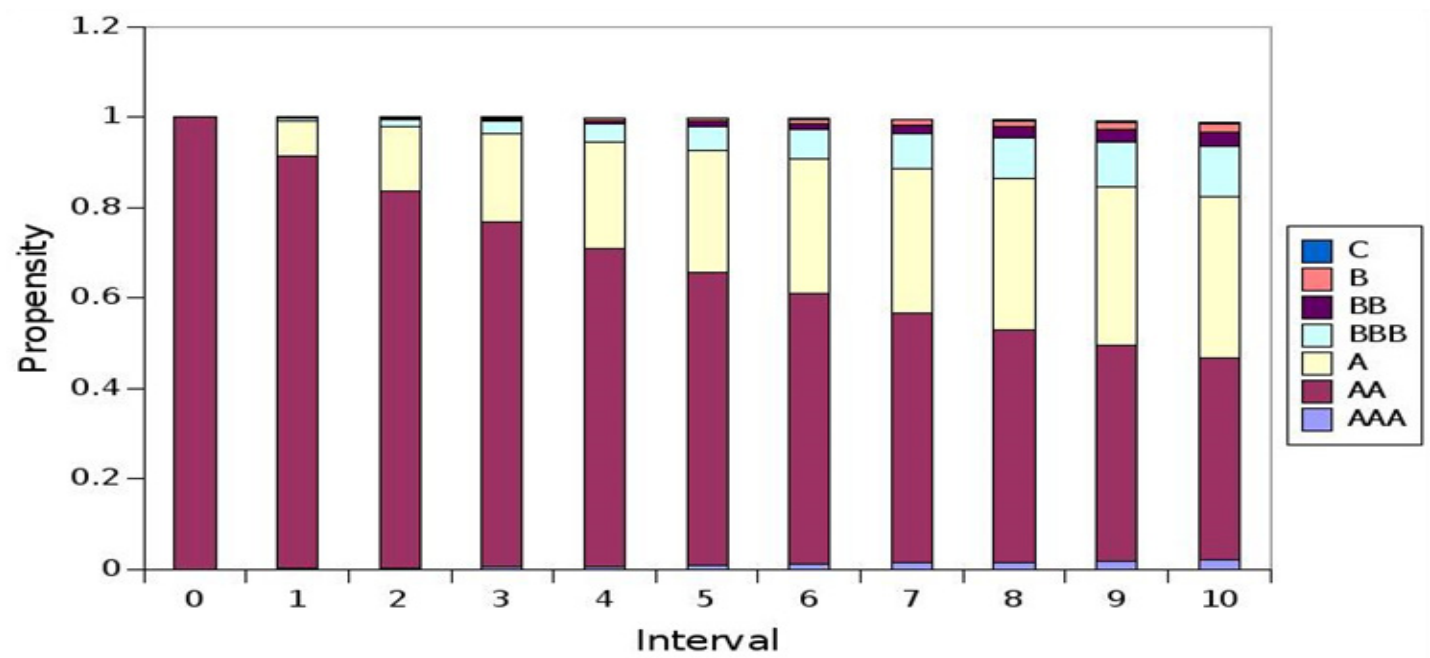

Figure 8. Interval propensity of a homogeneous portfolio with initial rating: AA

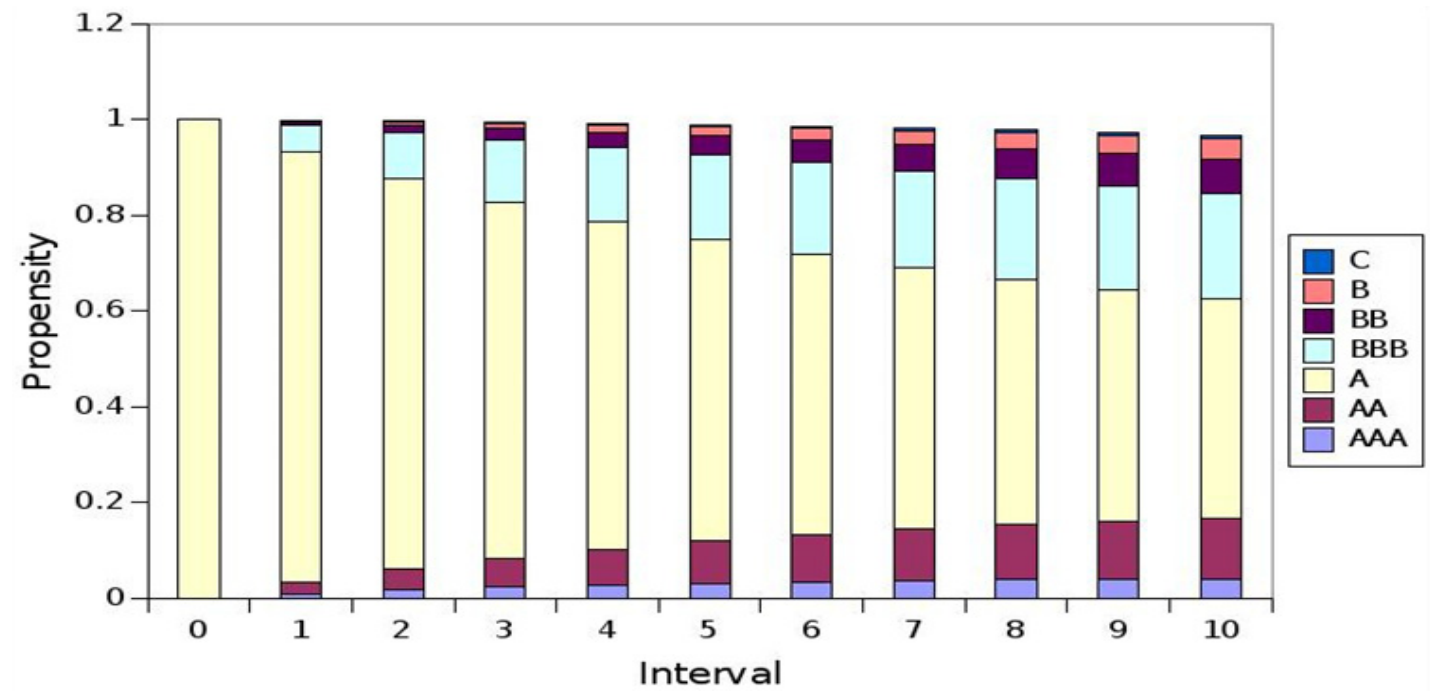

Figure 9. Interval propen sity of a homogeneous portfolio with initial rating: A 


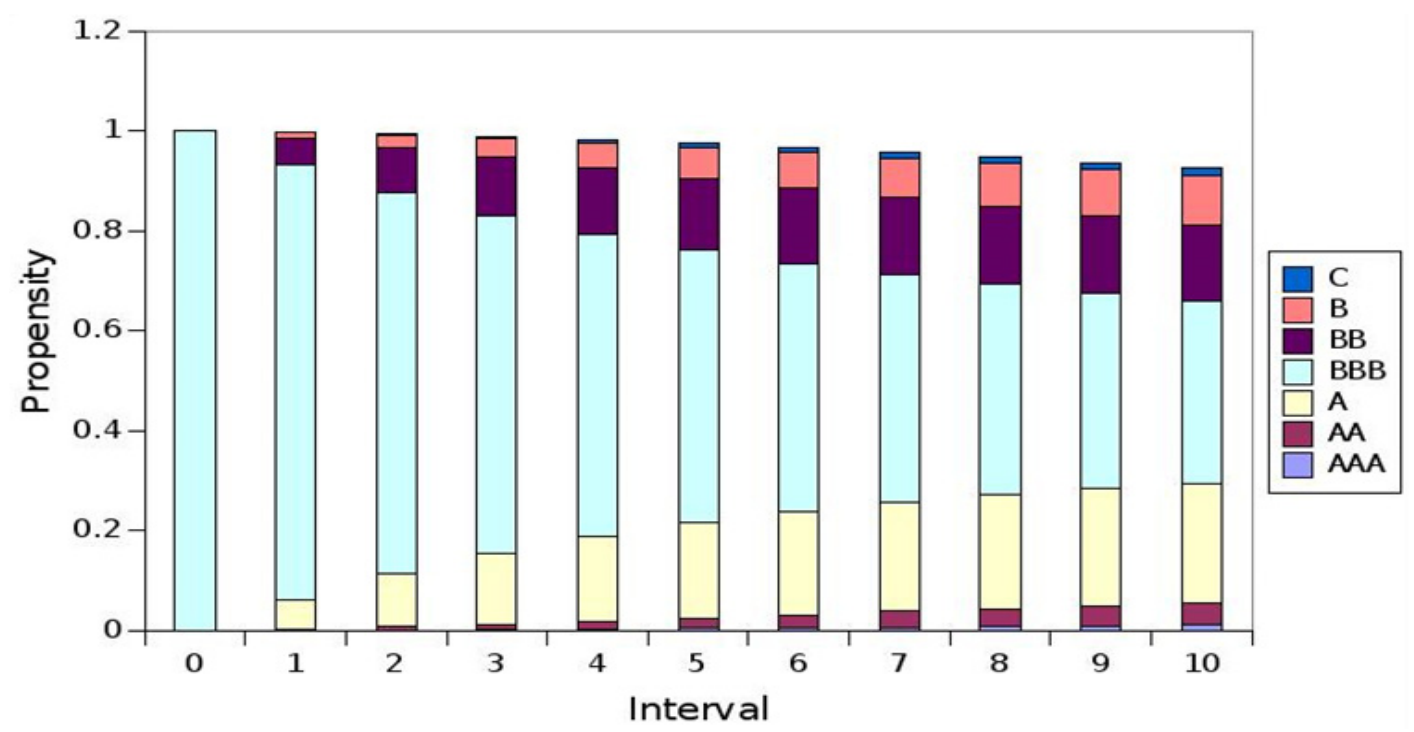

Figure 10. Interval propensity of a homogeneous portfolio with initial rating: BBB

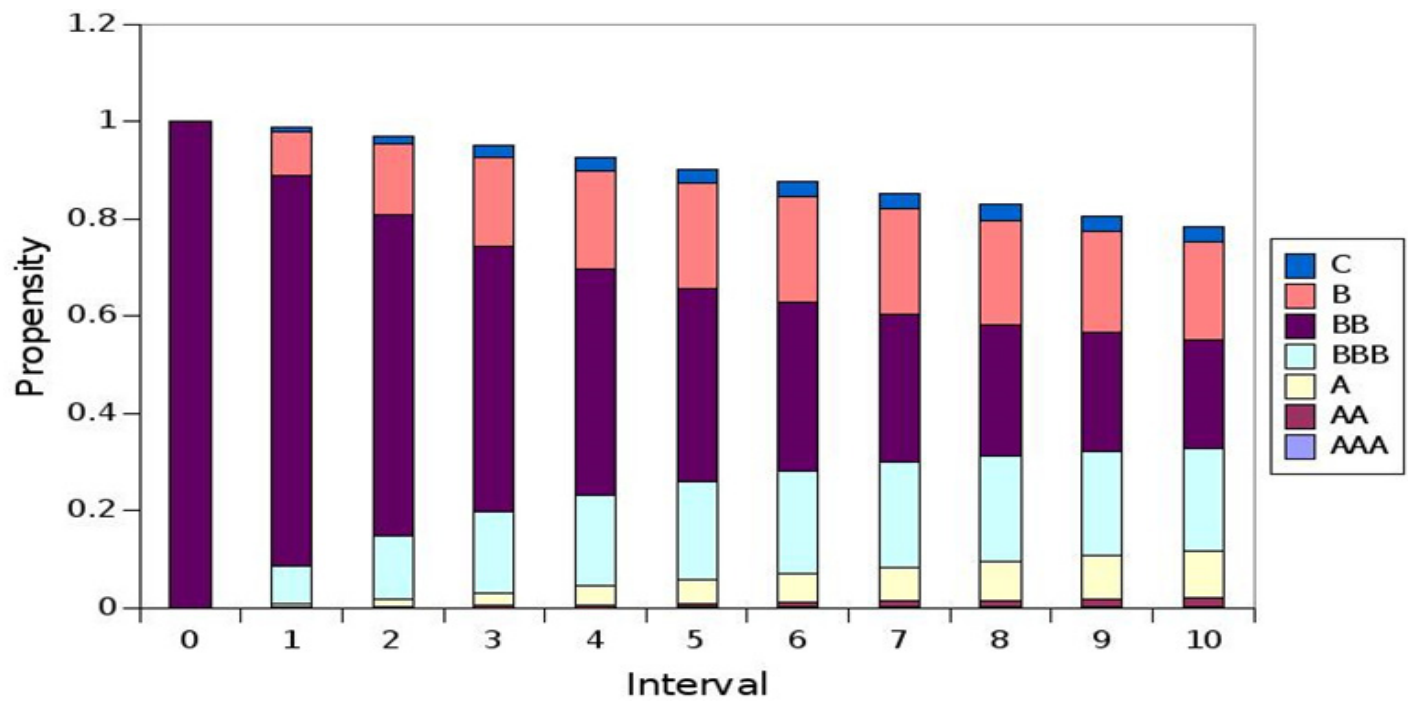

Figure 11. Interval propensity of a homogeneous portfolio with initial rating: BB

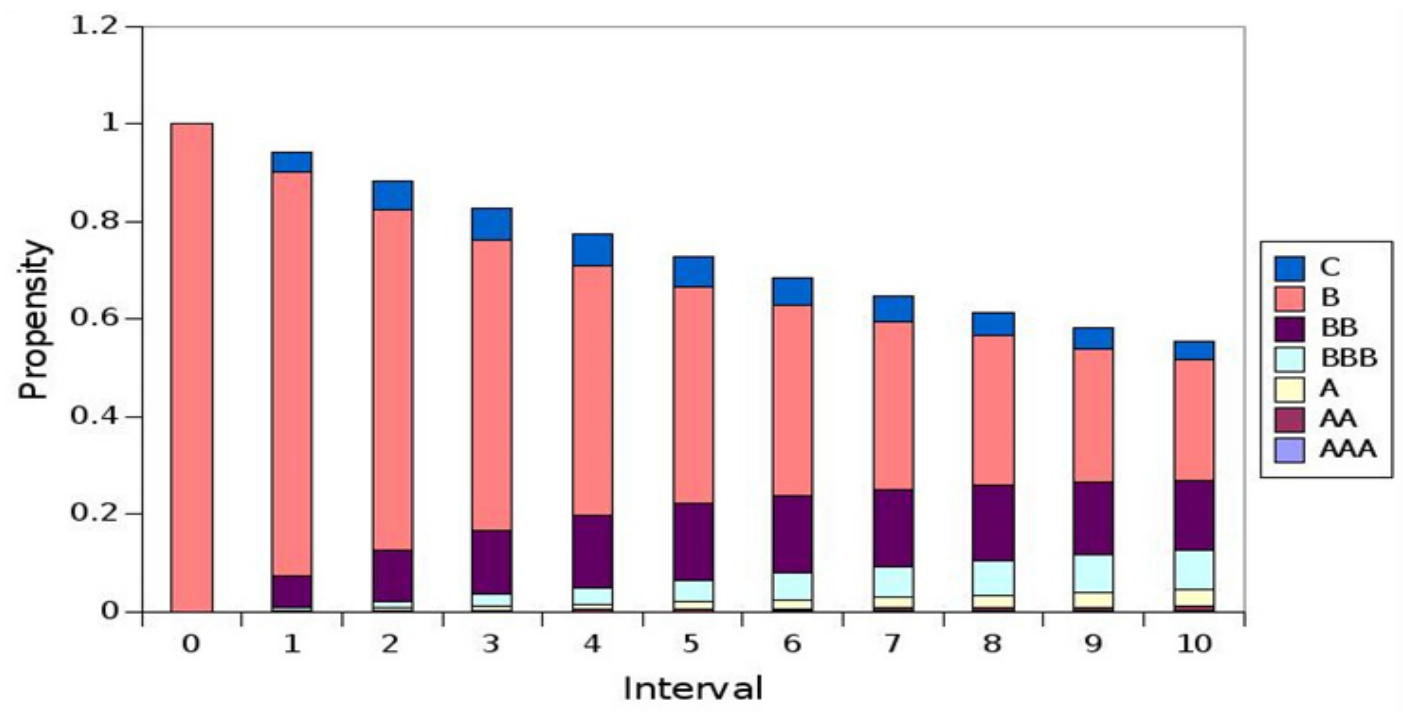

Figure 12. Interval propensity of a homogeneous portfolio with initial rating: B 


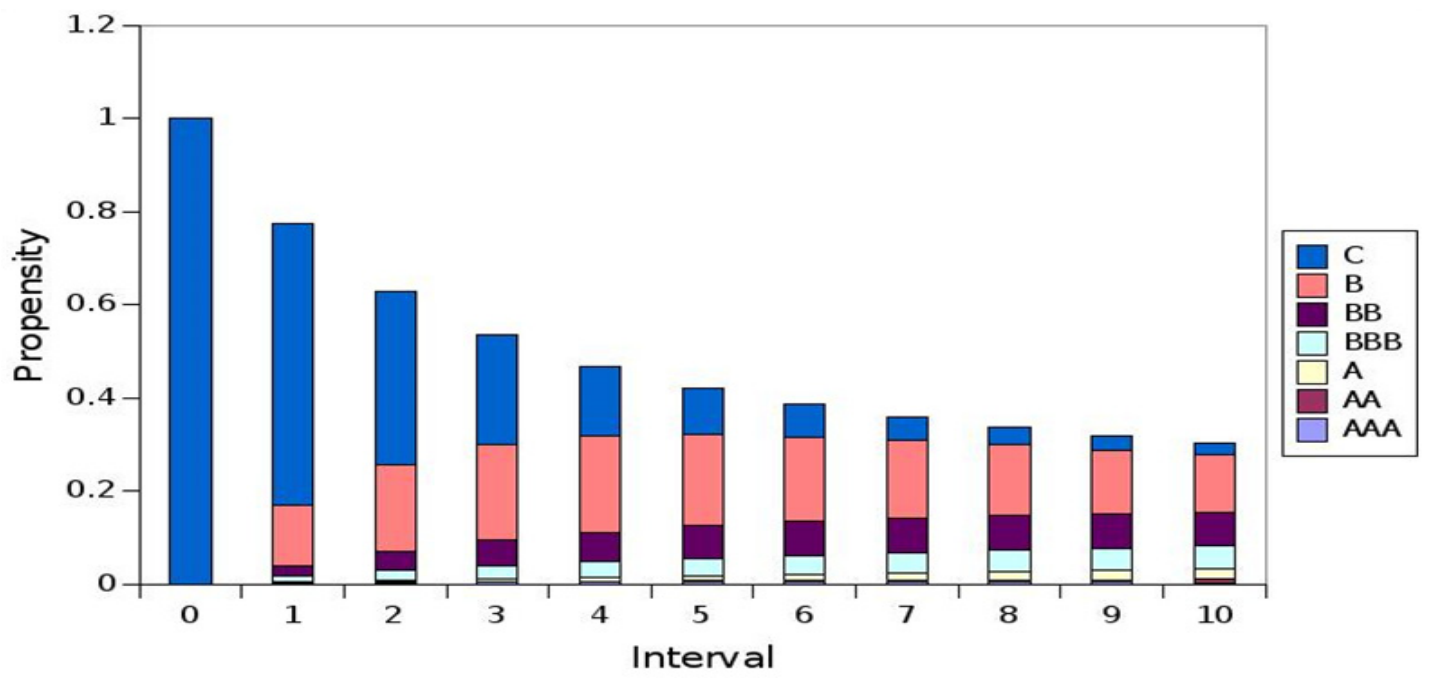

Figure 13. Interval propensity of a homogeneous portfolio with initial rating: $\mathrm{CCC}$

Figure 14 shows the net change in future value of the different ratings (equation 7). The value excludes value loss due to default, and is mainly influenced by interval rating propensity changes. The difference in spot rates between ratings also plays a significant role. The figure shows that lower ratings - CCC and B - are likely to experience an improvement in value, due to the bonds remaining in the portfolio being upgraded. Higher ratings are likely to experience a worsening in value, due to the bonds remaining in the portfolio worsening in terms of rating and thus credit quality. The value change increases with the time horizon, and is not really significant. However, it may point to the dynamics of the rating migration matrix - too high net value changes would imply an increase in default probabilities in subsequent intervals.

Figure 15 depicts the difference in yield rate between equation 1 and 3 - expanding the recovery component to make it dependent on the rating at default. The figure reveals an insignificant change. This is likely due to the nature of the per-interval distribution of ratings at default, coupled with the difference in recovery rate per rating category.

Figure 16 and 17 show the forward-rate based intensities of equation 6 . These figures contain the same values and only differ in terms of representation. Figure 18 and 19 show the difference in yield between the yield values obtained from equation 6 and the corresponding input or reference spot rate. For the higher quality ratings - AAA to BBB - the modelled value greatly corresponds with market value, judging by the similarity in yield. For the AAA and AA ratings, the yield structure is below the reference structure, and for the A and BBB ratings, the yield structure is above the reference structure. For the lower quality ratings - BB to CCC - the modelled value is significantly lower than market value, also reflected by the yield spread. If the equation is deemed accurate, and the input forward rates are deemed accurate, it should point to a discrepancy between the rating migration matrix used, and that implied by market prices, and utilized by the market.

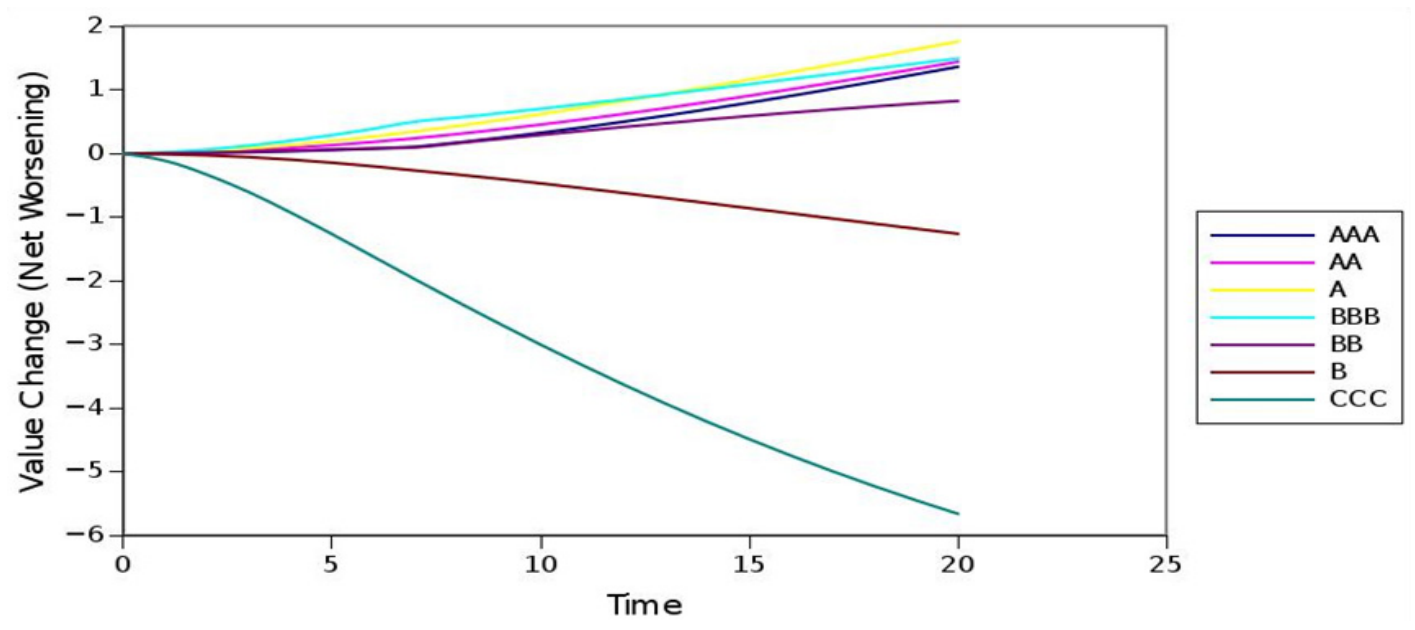

Figure 14. Net change in future value 


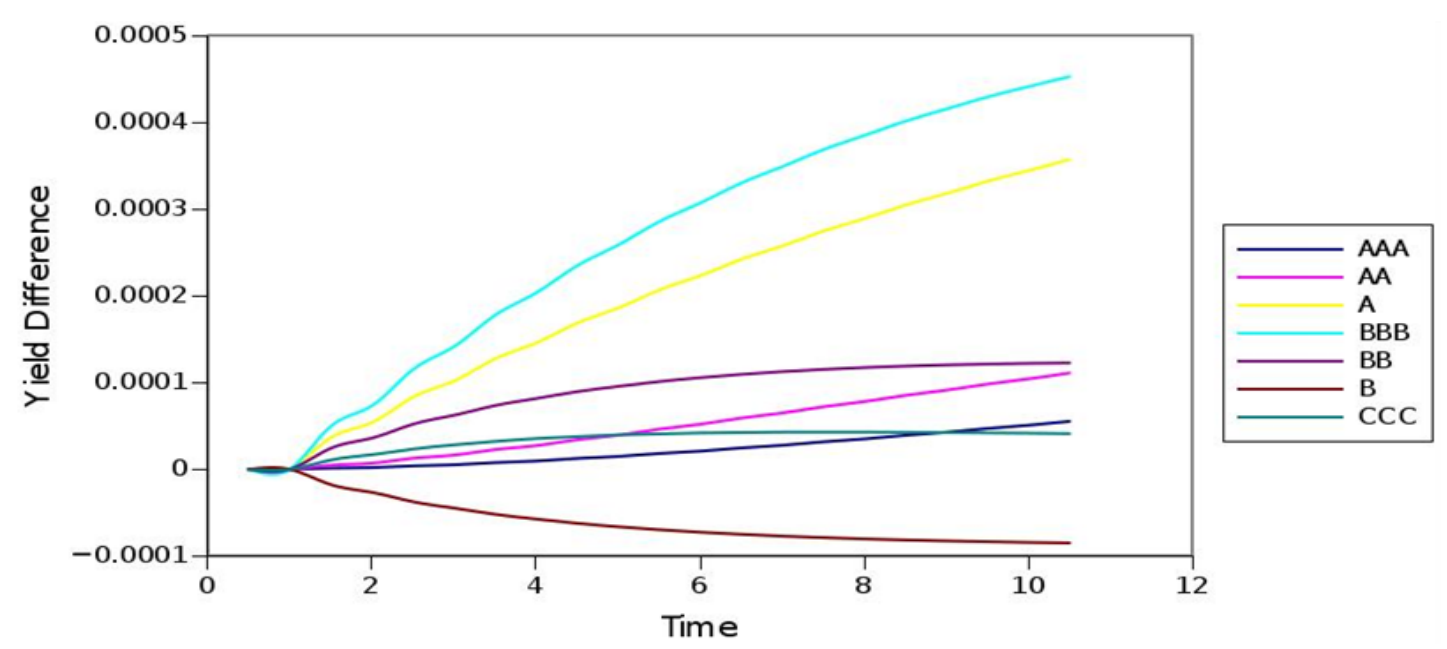

Figure 15. Yield change when basing recovery on credit rating on default

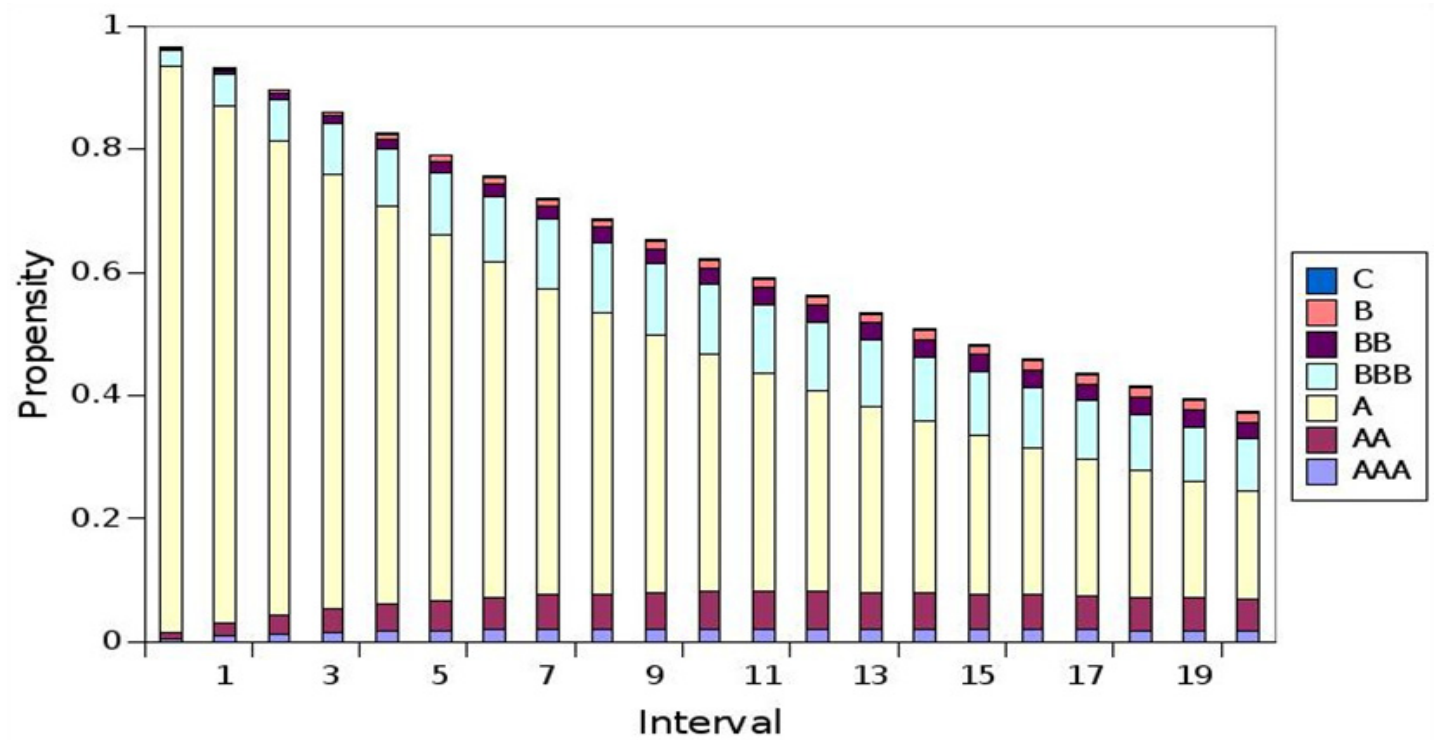

Figure 16. Forward-rate based interval intensity

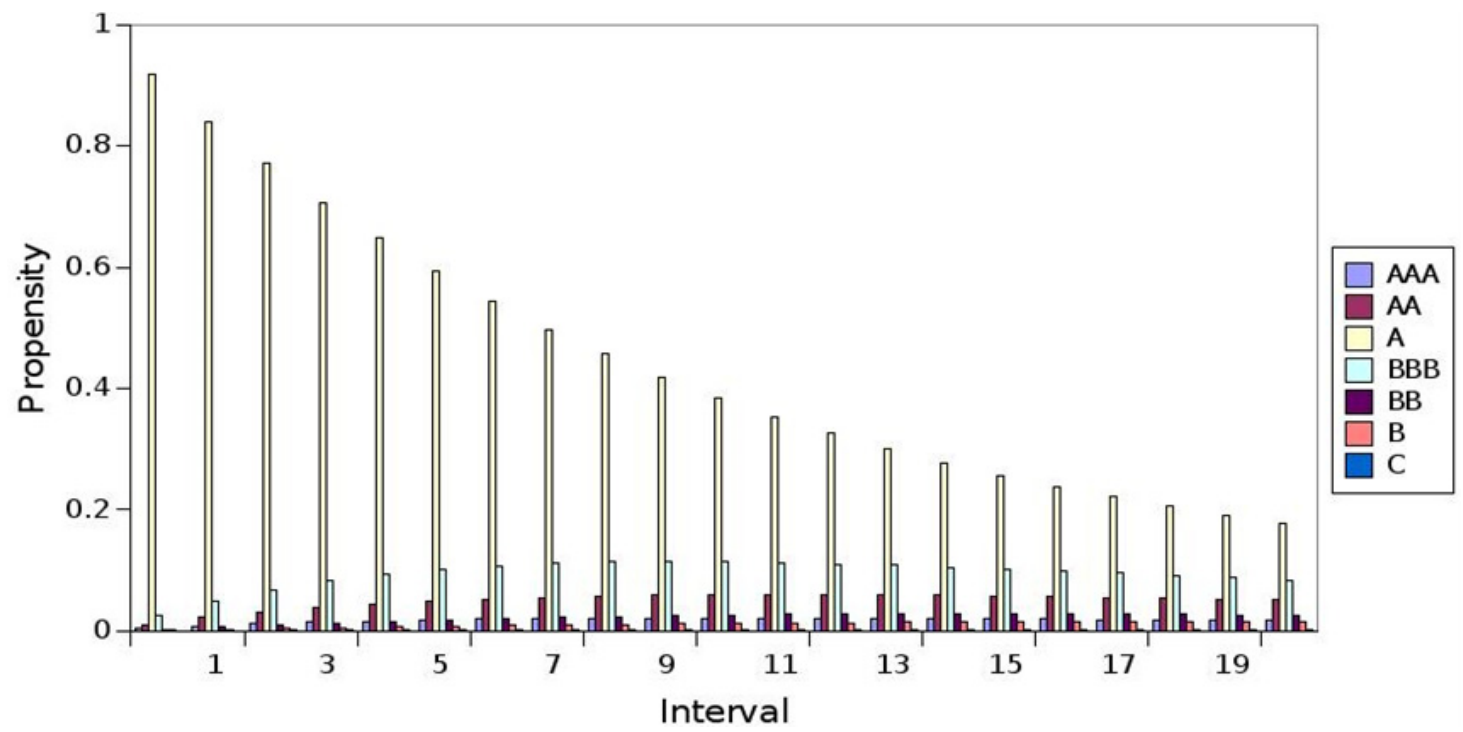

Figure 17. Forward-rate based interval intensity 


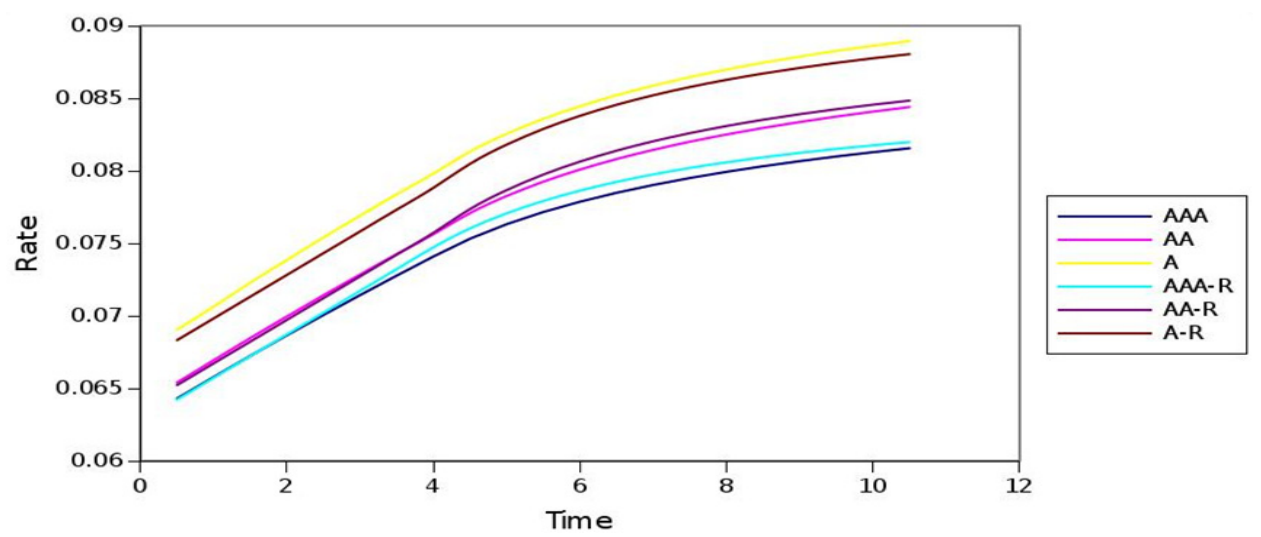

Figure 18. Modelled yield rate to reference spot rate (equation 6)

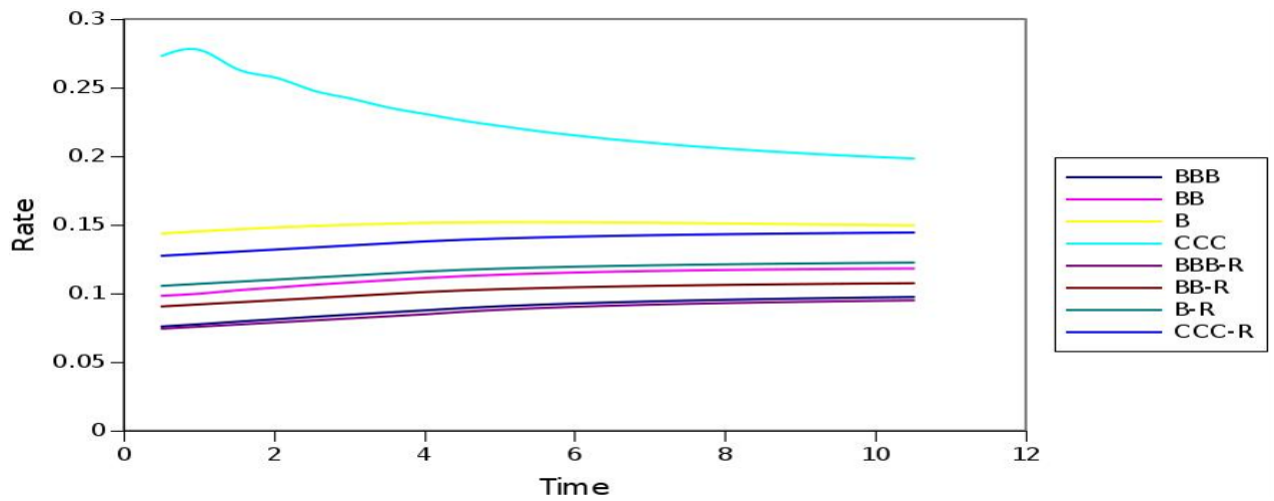

Figure 19. Modelled yield rate to reference spot rate (equation 6)

\section{Conclusion}

Default probability term structures - as the product of Markov chain processes or simply rating migration matrices - are composites of interval rating category propensities or intensities and per-rating migration to default probabilities. The default probabilities shape over intervals, particularly due to rating migration, and are thus interval - or time - dependent. Default probabilities of rating categories are not isolated from each other, but form composites across rating categories: the default probability of a rating category is not shaped only by the rating category's default probability and the rating category's rating migration matrix entry, in isolation of other rating categories' default probabilities and rating migration matrix entries, but in union therewith - in essence, the entire rating migration matrix.

Bonds of different credit quality (ratings), with default probability, but no rating migration probability, are perhaps easy and easier to value, but, at the same time, may be a hypothetical and elementary case. Rating migration brings a unique dimension to default probabilities as processes. Firstly, it signals prolonged credit quality changes, which leads to changes in probability of default, and is contrasted with default, which is rapid or immediate credit quality termination. Secondly, as a delayed process it influences rating category propensities and default probabilities of subsequent intervals. Also, it technically links the default probabilities and processes of different credit ratings. The cost implication of rating migration should be fully considered.

The implication of rating migration is that both terminating and intermediate interval rating category intensities are important - that rating migration estimates per interval should be accurate, as it influences subsequent default probability estimates. An accurate rating migration matrix would imply that both intermediate and terminating rating propensities are correctly estimated. The consequence is no potential for arbitrage between the option of keeping a (portfolio of) bond(s) and selling the (portfolio of) bond(s), for any interval. For correct valuation and valuation modelling each interval's default and non-default rating propensities should be accurate. Consequently, default probability estimates and bond value in general should be rather sensitive to rating migration probabilities.

A bond valuation model was proposed that values a bond according to its likely rating paths - default as well as non-default. The results were satisfactory, particularly for higher quality ratings. With reference to the market, the model under-values lower quality ratings. This may very well be due to the rating migration matrix used. Alternatively, it may be the forward rates used to value the rating paths. The study extracted forward rates from market rates to value interval rating paths. Overall, the bond valuation model offers a method of triangulation - valuing bonds this way should essentially correspond to valuing a bond according to expected cash flows, when considering the probability of default. 
The study utilized a rating migration matrix based on - calculated from - historical data. Historical data are free of uncertainty and should generally carry less (no) risk than (compared to) ahistorical data that are uncertain and risk-laden. Actual, perceived default probability should be higher than historically measured default probability, and historical estimates should demonstrate a tendency to under-value, and ahistorical estimates a tendency to over-value - only in ideal cases would the two meet. It should be possible to extract rating migration matrices from market prices, and a method to do so was delineated.

Historical rating migration matrices face a number of hurdles. First, the accuracy of historical rating migration matrices can and should be evaluated, in order to determine the accuracy of conclusions drawn from them. This can be done through simulation, and noting the extent historical rating migration matrices can forecast interval rating category intensities. To knowledge, this has not been considered before. If conclusions drawn from such rating migration matrices are deemed accurate, because the rating migration matrices are deemed accurate, the rating migration matrices should also be able to accurately forecast a period's rating migrations, including default.

Secondly, and perhaps more prominently, historical rating migration matrices need to overcome the historical-ahistorical dichotomy. With reference to the previous point, it is expected that historical rating migration matrices would fail to be ahistorically accurate - they would fail to be accurate when forward-looking or forward-applied. And even if they are ahistorically accurate, it can still be argued that they allow for little uncertainty. A basic consideration is how to include rating migration uncertainty into rating migration probabilities, and how to measure rating migration uncertainty. One answer is to simply increase the rating migration probabilities. From a different vantage point, historical rating migration matrices can be made sure (accurate) by including guarantees. The hypothetical use of options was briefly considered. The relative cost of such guarantees serves to support the historical-ahistorical pitfall and dilemma, and highlights that it is an area than needs consideration.

Extracting ahistorical rating migration matrices from market prices may mean that significant volatility resides across such extracted ahistorical rating migration matrices. This too may have a number of implications to consider. It may support views regarding uncertainty in rating migration estimates, including default, and it may indicate that ahistorical rating migration matrices move and update more rapidly than historical rating migration matrices. This forms another point that valuation models that utilize historical rating migration matrices should consider.

In general, rating migration based default probabilities demonstrate a term structure removed from interest rate term structures - some co-variance likely exists, but it is not complete. Economic outlooks may influence default probabilities via rating migration probabilities, and economic outlooks may influence rating migration probabilities just as well. This then also imply a unique (delayed) relationship between economic outlooks and default probability that should receive more attention. To incorporate economic outlooks into rating migration matrices, the rating migration matrix as a whole should likely be updated.

Rating migration offers a more detailed default process that structural models may find difficult to reproduce, particularly through modelling. This may very well give reduced form models an advantage over structural models.

Indirectly, a bond valuation model's accuracy should be related to its ability to forecast future ratings as proxies of credit quality.

\section{References}

Altman, E. I. (1989). Measuring corporate bond mortality and performance. The Journal of Finance, 44(4), 909-922. https://doi.org/10.1111/j.1540-6261.1989.tb02630.x

Altman, E. I. (1996). Rating Migration of Corporate Bonds: Comparative Results and Investor/Lender Implication.

Altman, E. I., \& Rijken, H. A. (2004). How rating agencies achieve rating stability. Journal of Banking \& Finance, 28(11), 2679-2714. https://doi.org/10.1016/j.jbankfin.2004.06.006

Amato, J. D., \& Furfine, C. H. (2004). Are credit ratings procyclical?. Journal of Banking \& Finance, 28(11), 2641-2677. https://doi.org/10.1016/j.jbankfin.2004.06.005

Athanassakos, G., \& Carayannopoulos, P. (2001) An empirical analysis of the relationship of bond yield spreads and macro economic factors. Applied Financial Economics, 11(2), 197-207. https://doi.org/10.1080/096031001750071596

Bangia, A., Diebold, F. X., Kronimus, A., Schagen, C., \& Schuermann, T. (2002). Ratings migration and the business cycle, with application to credit portfolio stress testing. Journal of Banking \& Finance, 26(2), 445-474. https://doi.org/10.1016/S0378-4266(01)00229-1

Belkaoui, A. (1980). Industrial bond ratings: A new look. Financial Management, 44-51. https://doi.org/10.2307/3664892 
Benkert, C. (2004). Explaining credit default swap premia. Journal of Futures markets, 24(1), 71-92. https://doi.org/10.1002/fut.10112

Blanco, R., Brennan, S., \& Marsh, I. W. (2005). An empirical analysis of the dynamic relation between investmentgrade bonds and credit default swaps. The Journal of Finance, 60(5), 2255-2281. https://doi.org/10.1111/j.1540-6261.2005.00798.x

Campbell, J. Y., \& Taksler, G. B. (2003). Equity volatility and corporate bond yields. The Journal of Finance, 58(6), 2321-2350. https://doi.org/10.1046/j.1540-6261.2003.00607.x

Cantor, R., Packer, F., \& Cole, K. (1997). Split ratings and the pricing of credit risk. The Journal of Fixed Income, 7(3), 72-82. https://doi.org/10.3905/jfi.1997.408217

Chan, K., \& Jegadeesh, N. (2004). Market-based evaluation for models to predict bond ratings. Review of Pacific Basin Financial Markets and Policies, 7(02), 153-172. https://doi.org/10.1142/S0219091504000081

Collin-Dufresne, P., Goldstein, R. S., \& Martin, J. S. (2001). The determinants of credit spread changes. The Journal of Finance, 56(6), 2177-2207. https://doi.org/10.1111/0022-1082.00402

Das, S., \& Tufano, P. (1995). "Pricing Credit Sensitive Debt When Interest Rates, Credit Ratings, and Credit Spreads Are Stochastic," Journal of Financial Engineering, 5, 161-198.

Delianedis, G., \& Geske, R. L. (2003). February. Credit risk and risk neutral default probabilities: information about rating migrations and defaults. In EFA 2003 annual conference paper (No. 962).

Duffee, G. R. (1999). Estimating the price of default risk. Review of Financial Studies, 12(1),197-226. https://doi.org/10.1093/rfs/12.1.197

Duffie, D., \& Singleton, K. J. (1999). Modeling term structures of defaultable bonds. Review of Financial studies, 12(4), 687-720. https://doi.org/10.1093/rfs/12.4.687

Ederington, L. H., \& Goh, J. C. (1998). Bond rating agencies and stock analysts: who knows what when?. Journal of Financial and Quantitative Analysis, 33(04), 569-585. https://doi.org/10.2307/2331132

Elton, E. J., Gruber, M. J., Agrawal, D., \& Mann, C. (2001). Explaining the Rate Spread on Corporate Bonds. The Journal of Finance, 56(1). https://doi.org/10.1111/0022-1082.00324

Elton, E. J., Gruber, M. J., Agrawal, D., \& Mann, C. (2004). Factors affecting the valuation of corporate bonds. Journal of Banking \& Finance, 28(11), 2747-2767. https://doi.org/10.1016/j.jbankfin.2004.06.008

Elton, J. E. (1999). Expected return, realized return and asset pricing tests. Journal of Finance, 4, 1199-1220. https://doi.org/10.1111/0022-1082.00144

Eom, Y. H., Helwege, J., \& Huang, J. Z. (2004). Structural models of corporate bond pricing: An empirical analysis. Review of Financial studies, 17(2), 499-544. https://doi.org/10.1093/rfs/hhg053

Ericsson, J., Jacobs, K., \& Oviedo, R. (2009). The determinants of credit default swap premia. Journal of Financial and Quantitative Analysis, 44(1), 109-132. https://doi.org/10.1017/S0022109009090061

Fama, E. F., \& French, K. R. (1993). Common risk factors in the returns on stocks and bonds. Journal of financial economics, 33(1), 3-56. https://doi.org/10.1016/0304-405X(93)90023-5

Fei, F., Fuertes, A. M., \& Kalotychou, E. (2012). Credit rating migration risk and business cycles. Journal of Business Finance \& Accounting, 39(1-2), 229-263. https://doi.org/10.1111/j.1468-5957.2011.02272.x

Foss, G. W. (1995). Quantifying risk in the corporate bond markets. Financial Analysts Journal, 51(2), 29-34. https://doi.org/10.2469/faj.v51.n2.1878

Frydman, H., \& Schuermann, T. (2008). Credit rating dynamics and Markov mixture models. Journal of Banking \& Finance, 32(6), 1062-1075. https://doi.org/10.1016/j.jbankfin.2007.09.013

Geske, R. L., \& Delianedis, G. (2001). The components of corporate credit spreads: Default, recovery, taxes, jumps, liquidity, and market factors.

Grandes, M., \& Peter, M. (2005). How Important is Sovereign Risk in Determining Corporate Credit Spreads in Emerging Markets? The Case of Local Currency Bonds in South Africa. IMF Working Paper 217.

Hamilton, D. T., \& Cantor, R. (2004). Rating transition and default rates conditioned on outlooks. Journal of Fixed Income, 14(2), 54-70. https://doi.org/10.3905/jfi.2004.439837

Hines, M. A., Ang, J. S., \& Patel, K. A. (1975). Bond rating methods: Comparison and validation. The Journal of Finance, 30(2), 631-640. https://doi.org/10.1111/j.1540-6261.1975.tb01836.x 
Houweling, P., \& Vorst, T. (2005). Pricing default swaps: Empirical evidence. Journal of International Money and Finance, 24(8), 1200-1225. https://doi.org/10.1016/j.jimonfin.2005.08.009

Houweling, P., Mentink, A., \& Vorst, T. (2005). Comparing possible proxies of corporate bond liquidity. Journal of Banking \& Finance, 29(6), 1331-1358. https://doi.org/10.1016/j.jbankfin.2004.04.007

Huang, J. Z., \& Huang, M. (2012). How much of the corporate-treasury yield spread is due to credit risk?. Review of Asset Pricing Studies, 2(2), 153-202. https://doi.org/10.1093/rapstu/ras011

Jarrow, R. A., \& Turnbull, S. M. (1995). Pricing derivatives on financial securities subject to credit risk. The journal of finance, 50(1), 53-85. https://doi.org/10.1111/j.1540-6261.1995.tb05167.x

Jarrow, R. A., Janosi, T., \& Yildirim, Y. (2002). Estimating expected losses and liquidity discounts implicit in debt prices. Journal of Risk, 5(1).

Jarrow, R. A., Lando, D., \& Turnbull, S. M. (1997). A Markov model for the term structure of credit risk spreads. Review of Financial studies, 10(2), 481-523. https://doi.org/10.1093/rfs/10.2.481

Kadam, A., \& Lenk, P. (2008). Bayesian inference for issuer heterogeneity in credit ratings migration. Journal of Banking \& Finance, 32(10), 2267-2274. https://doi.org/10.1016/j.jbankfin.2007.12.043

Kaplan, R. S., \& Urwitz, G. (1979). Statistical models of bond ratings: A methodological inquiry. Journal of business, 231-261. https://doi.org/10.1086/296045

Kim, H., Ramaswamy, K., \& Sunderesan, S. (1993), "Valuation of Corporate Fixed-Income Securities". Financial Management (Special issue on financial distress), 22(3), 60-78.

Kumar, K., \& Haynes, J. D. (2003). Forecasting credit ratings using an ANN and statistical techniques. International journal of business studies, 11(1).

Lando, D., \& Skødeberg, T. M. (2002). Analyzing rating transitions and rating drift with continuous observations. journal of banking \& finance, 26(2), 423-444. https://doi.org/10.1016/S0378-4266(01)00228-X

Longstaff, F. A., \& Eduardo, S. S. (1995), A simple approach to valuing risky fixed and floating rate debt. Journal of Finance 50, 789-819. https://doi.org/10.1111/j.1540-6261.1995.tb04037.x

Longstaff, F. A., Mithal, S., \& Neis, E. (2005). Corporate yield spreads: Default risk or liquidity? New evidence from the credit default swap market. The Journal of Finance, 60(5), 2213-2253. https://doi.org/10.1111/j.1540-6261.2005.00797.x

Manzoni, K. (2004). Modeling Eurobond credit ratings and forecasting downgrade probability. International Review of Financial Analysis, 13(3), 277-300. https://doi.org/10.1016/j.irfa.2004.02.010

Marciniak, M. (2006). Yield curve estimation at the National Bank of Poland. Bank i Kredyt; 10, 52-74

Merton, R. (1974). On the pricing of corporate debt: the risk structure of interest rates. Journal of Finance, 29(2) 449-70.

Nelson, C. R., \& Siegel, A. F. (1987). Parsimonious modeling of yield curves. Journal of business, 473-489. https://doi.org/10.1086/296409

Nickell, P., Perraudin, W., \& Varotto, S. (2000), "Stability of Rating Transitions". Journal of Banking \& Finance, 24, 203-227. https://doi.org/10.1016/S0378-4266(99)00057-6

Norden, L., \& Weber, M. (2009). The co-movement of credit default swap, bond and stock markets: An empirical analysis. European financial management, 15(3), 529-562. https://doi.org/10.1111/j.1468-036X.2007.00427.x

Wang, Z. (2004). Financial ratio selection for default-rating modeling: a model-free approach and its empirical performance. Journal of Applied Finance, 14(1).

Weistroffer, C., Speyer, B., Kaiser, S., \& Mayer, T. (2009). Credit default swaps. Deutsche bank research.

Zhu, H. (2006). An empirical comparison of credit spreads between the bond market and the credit default swap market. Journal of Financial Services Research, 29(3), 211-235. https://doi.org/10.1007/s10693-006-7626-x

\section{Copyrights}

Copyright for this article is retained by the author(s), with first publication rights granted to the journal.

This is an open-access article distributed under the terms and conditions of the Creative Commons Attribution license which permits unrestricted use, distribution, and reproduction in any medium, provided the original work is properly cited. 